Portland State University

PDXScholar

\title{
Suspended Sediment Fluxes at an Intertidal Flat: The Shifting Influence of Wave, Wind, Tidal, and Freshwater Forcing
}

Stefan A. Talke

Portland State University, talke@pdx.edu

Mark T. Stacey

University of California at Berkeley

Follow this and additional works at: https://pdxscholar.library.pdx.edu/cengin_fac

Part of the Civil Engineering Commons, and the Environmental Engineering Commons Let us know how access to this document benefits you.

\section{Citation Details}

Talke, Stefan A. and Stacey, Mark T., "Suspended Sediment Fluxes at an Intertidal Flat: The Shifting Influence of Wave, Wind, Tidal, and Freshwater Forcing" (2008). Civil and Environmental Engineering Faculty Publications and Presentations. 84.

https://pdxscholar.library.pdx.edu/cengin_fac/84

This Post-Print is brought to you for free and open access. It has been accepted for inclusion in Civil and Environmental Engineering Faculty Publications and Presentations by an authorized administrator of PDXScholar. Please contact us if we can make this document more accessible: pdxscholar@pdx.edu. 


\title{
Suspended sediment fluxes at an intertidal flat: The shifting influence of wave, wind, tidal, and freshwater forcing
}

\author{
Stefan A. Talke ${ }^{1}$, Mark T. Stacey ${ }^{2}$
}

(1): Institute for Marine and Atmospheric research, University of Utrecht, Princetonplein 5, 3584 CC Utrecht, the Netherlands, e-mail: s.a.talke@phys.uu.nl

(2): Department of Civil and Environmental Engineering, University of California at Berkeley, Berkeley, CA, 94720 USA e-mail: $\underline{\text { m.stacey@berkeley.edu }}$

Keywords: Intertidal Mudflat, Sediment Transport, Waves, Tides, Seiching, USA, California, San Francisco Bay

\begin{abstract}
Using in-situ, continuous, high frequency $(8-16 \mathrm{~Hz})$ measurements of velocity, suspended sediment concentration (SSC), and salinity, we investigate the factors affecting near-bed sediment flux during and after a meteorological event (cold front) on an intertidal flat in central San Francisco Bay. Hydrodynamic forcing occurs over many frequency bands including wind-wave, ocean swell, seiching (500-1000 second), tidal, and infra-tidal frequencies, and varies greatly over the time scale of hours and days. Sediment fluxes occur primarily due to variations in flow and SSC at three different scales: residual (tidally averaged), tidal, and seiching. During the meteorological event, sediment fluxes are dominated by increases in tidally-averaged SSC and flow. Runoff and wind-induced circulation contribute to an order of magnitude increase in tidally averaged offshore flow, while waves and seiching motions from wind forcing cause an order of magnitude increase in tidally averaged SSC. Sediment fluxes during calm periods are dominated by asymmetries in SSC over a tidal cycle. Freshwater forcing produces sharp salinity fronts which trap sediment and sweep by the sensors over short ( 30 minute) time scales, and occur primarily during the flood. The resulting flood dominance in SSC is magnified or reversed by variations in windforcing between the flood and ebb. Long term records show that more than half of wind events (sustained speeds of greater than $5 \mathrm{~m} / \mathrm{s}$ ) occur for three hours or less, suggesting that asymmetric wind forcing over a tidal cycle commonly occurs. Seiching associated with wind and its variation produces onshore sediment transport. Overall, the changing hydrodynamic and meteorological forcing influence sediment flux at both short (minutes) and long (days) time scales.
\end{abstract}

\section{Introduction}

Intertidal flats form a boundary between land and sea, and are important feeding grounds for birds, fish, and other biota. Moreover, due to their proximity to cities and industrial areas, intertidal flats may contain buried contaminants that are uncovered by storm events and longterm morphological change. Thus, the physical processes that create, erode and rework intertidal flats are immensely important from both an ecological and practical viewpoint.

Previous studies have suggested that the primary forces shaping intertidal flats are windinduced waves and tidal currents. The shifting influence of wind has generally been reduced 
to three distinct levels of forcing conditions: stormy, windy, and calm (Shi and Chen, 1996, Le Hir et al, 2000, Janssen- Stelder, 2000). During storms, large waves are observed to erode sediment and keep sediment in suspension during the slack tide, which is then available to be transported offshore during the ebb (Le Hir et al, 2000, Dyer et al, 2000, Bassoullet et al, 2000, Andersen \& Perjup, 2001). Storms may also deposit sediments onto upland marshes (e.g., Yang et al, 2003, and list therein). During windy periods, local erosion generally results in offshore transport (Christie et al., 1999), Dyer et al., 2000, de Jonge and van Beusekom, 1995), though net transport can be onshore as well (e.g., de Haas and Eisma, 1993). During calm periods, net transport is observed to be onshore (Black, 1998, Christie et al., 1999, Dyer et al, 2000, Le Hir et al., 2000, Ridderinkhof et al, 2000), which is attributed to settling lag and scour lag effects (Christie et al, 1999). Sediment is observed to be eroded during the flood tide, is transported shoreward, and settles out during the high-water slack period (Christie et al, 1999; de Haas \& Eisma, 1993; Ridderinkhof et al. 2000). Because ebb currents are insufficient to resuspend and transport all the recently deposited sediment (even in an ebb dominated estuary such as the Dollard, NL), accretion occurs in calm periods (Dyer et al, 2000).

Models of sediment transport have provided important insights into intertidal processes by focusing on the effects of tidal currents (Friedrichs \& Aubrey, 1996, Pritchard et al., 2002, Pritchard \& Hogg., 2003), or the combined affect of winds and tidal currents (Ridderinkhof, 1998, Roberts et al., 2000, Waeles et al., 2004). Sediment fluxes are found to occur due to tidal asymmetries in velocity (e.g., Ridderinkhof, 1998, Roberts et al., 2000, Pritchard et al., 2002) and due to settling lag effects (e.g., Pritchard \& Hogg, 2003). Ridderinkhof (1998) concludes that asymmetries in tidal velocities (rather than waves) set the direction of sediment flux, and that waves reduce net sediment flux by keeping sediment in suspension over a tidal cycle. Waeles et al. (2004) finds that even small (but constantly applied) waves of $5 \mathrm{~cm}$ cause an export of sediment that is balanced by input at the seaward boundary. All models that include wave effects apply constant forcing over a tidal period (e.g., Ridderinkhof, 1998, Roberts et al., 2000, Waeles et al., 2004).

Other factors besides wind waves and tidal currents are observed to play a role in sediment erosion and transport over a tidal time scale. Ridderinkhof et al. (2000) and de Haas and Eisma (1993) note that storm surge increases SSC and offshore transport in the Ems/Dollard estuary. Storm surge also increases the influx of sediments to upland marshes, particularly during spring tides (Yang et al, 2003). Christiansen et al. (2006) found that asymmetries in tidal velocity caused by winds of 4-12 m/s dominated sediment fluxes at a tidal flat in the Wadden Sea. Freshwater flow from upland watersheds or local rain runoff affects the mean current, as can local circulation patterns, nonlinear waves (Stokes drift), wind stress, and many other sources (Le Hir et al., 2000). Changes to the supply of sediment (Ridderinkhof et al 2000, Wright and Schoellhamer, 2004) or the critical stress of erosion (Kornman and de Deckere, 1998, Staats et al, 2001, O’Brien et al., 2000, Dyer, 1998) are important components of the long-term sediment balance. All these factors show that erosion, deposition, and transport are subject to many changeable parameters.

In this contribution we explore the subtle effects of changes in hydrodynamic and meteorological forcing from short time scales (wave time scale) to longer time scales (days) on an intertidal flat in San Francisco Bay. We investigate the mechanisms that elevate SSC, including waves, tidal currents, seiching motions, and freshwater forcing, and evaluate the time scales over which SSC and velocity vary. In turn we highlight how variations at both tidally-averaged and intra-tidal time scales affect net sediment fluxes during a meteorological 
event (cold front) and a relatively calmer period. We show that the relative phasing (timing) and time-scales of wind, tidal and freshwater forcing can completely alter the net flux of sediment in the intertidal zone, even between consecutive tidal periods.

In Section 2 we describe the experiment site and measurement methods, while in section 3 we describe the hydrographic results and explore the variations of SSC and sediment flux. In section 4 we analyze sediment flux at the tidally averaged and tidally varying time scales, and the conclusions are presented in section 5.

\section{Methods}

The intertidal flat we investigate in this study is situated in the central San Francisco Bay near the city of Richmond, CA (figure 1a). Along its east and west borders, the intertidal flat is fringed by marshland (figure 1b) that lies behind an outer seawall. The northern border is a rip-rap seawall. Two subtidal channels drain the upland marsh system and combine together within the intertidal flat. The southern side of the intertidal flat, roughly $200 \mathrm{~m}$ in diameter, is open to the central San Francisco Bay. The sediment is dominated by fine sand and silt, and shape of the mudflat morphology is convex upwards, consistent with an accretionary flat (Dyer, 1998, Le Hir et al, 2000, Kirby, 2000). Ripples with a wavelength of 0.05-0.06 m and a height of 0.01-0.02 m occur on the flat.

Over a four day period beginning at 16:00 hrs (local time) on April 11, 2003 and ending at 17:00 hrs on April 15 $5^{\text {th }}, 2003$ we deployed an array of hydrodynamic sensors on a sawhorse frame (figure 2) located at the opening of the flat to the bay (see figure 1). The frame was located about $50 \mathrm{~m}$ west of the subtidal channel, and oriented along the primary (NorthSouth) stream axis. The frame is thus optimally oriented to observe fluxes between the central bay and the flat. On the frame we deployed 6 Acoustic Doppler Velocimeters (ADVs), 3 optical backscatter sensors (OBS) from D\&A instruments, 3 ConductivityTemperature-Depth sensors (CTDs), and 2 combined OBS/Fluorometers. The OBS was calibrated by Ralston (2005) using estimates of SSC found from co-located, in-situ water samples.

The velocimeters and turbidity sensors were located at heights between $0.01 \mathrm{~m}$ and $0.35 \mathrm{~m}$ off the bed, and measured a new, synchronous 'burst' of data every 10 minutes. Nearly continuous velocity data (burst length of 590 seconds) was measured at heights of $0.16 \mathrm{~m}$ and $0.28 \mathrm{~m}$ at a frequency of $8 \mathrm{~Hz}$, and was synchronized with OBS sensors at $0.05 \mathrm{~m}$ and $0.19 \mathrm{~m}$. The accuracy of the velocimeters is estimated by the manufacturers to be $0.001 \mathrm{~m} / \mathrm{s}$. Because of memory and battery constraints, the remaining velocimeters measured for burst lengths of either 188 seconds (side-mounted) or 345 seconds. A small portion (order of 10-20 minutes) of each flood and ebb period was missed until the sensors were immersed. Additionally, the side-mounted velocimeters $(0.1 \mathrm{~m}$ and $0.33 \mathrm{~m}$ off bed $)$, the two lower downward facing velocimeters $(0.01 \mathrm{~m}$ and $0.05 \mathrm{~m}$ off bed $)$, and the lower OBS $(0.05 \mathrm{~m}$ off bed) failed during the large cold front that occurred from April $11^{\text {th }}$-April $13^{\text {th }}, 2003$. Finally, during the cold front, changes to the relative bed-level of $0.05 \mathrm{~m}$ to $0.1 \mathrm{~m}$ (the frame settled into the sediment) biased velocity and SSC measurements. The frame was repositioned relative to the bed after tide 4 to the initial specifications. Because of the data limitations, we focus on mechanisms of near-bed suspended sediment transport for the velocity/SSC pair deployed at $0.16 \mathrm{~m}$ and 0.19 $\mathrm{m}$, realizing that the height off the bed was $\mathrm{O}(0.1 \mathrm{~m})$ during portions of the meteorological event. 
150

151

152

153

154

155

156

157

158

159

160

161

162

163

164

165

166

167

168

169

170

171

172

173

174

175

176

177

178

179

180

181

182

183

184

185

186

187

188

189

190

191

192

193

194

195

196

197

198

199

We obtained hourly wind speed data from a meteorological station located $\sim 1 \mathrm{~km}$ from the experiment site (Bay Area Air Quality Management District station 2950). Water level data was obtained from NOAA buoy 9414863 at the Chevron Oil Pier in Richmond. The publicly available tidal prediction software Jtides was used to compare predicted tidal levels to the actually measured tidal levels.

\section{Results}

Below we describe the hydrodynamic conditions prevalent during the experiment, and the sediment fluxes resulting from them. Because hydrodynamic conditions varied during the meteorological event (hour 0-50) and afterwards (hour 50-100), we summarize the hydrographic conditions in Fig. 3 and Fig. 4, respectively.

\subsection{Hydrographic conditions}

The central San Francisco Bay is forced by semi-diurnally varying tides with a maximum tidal range of $\sim 2 \mathrm{~m}$. During the first four tidal periods (Fig. 3a) of the experiment, the diurnal inequality is evident in the water-level amplitude $(1.1 \mathrm{~m}-1.5 \mathrm{~m})$, while by contrast the second four tides are nearly equal in amplitude ( 1.5 m; Fig. 4a). The cross-shore, north-south tidal current $V_{30}$, as measured by a 30 minute moving average, typically exhibits a maximum of $0.07 \mathrm{~m} / \mathrm{s}-0.11 \mathrm{~m} / \mathrm{s}$ with-in an hour of wetting or drying (see Fig. $3 \mathrm{~b}$ and $4 \mathrm{~b}$ ), with the exception of an ebb flow of $0.25 \mathrm{~m} / \mathrm{s}$ during the late ebb at $t=20-21$ hours (Fig. 3b).

Between April $11^{\text {th }}$ and April 13 ${ }^{\text {th }}, 2003$, a large cold front passed through the San Francisco Bay area. The peak of the meteorological event occurred between $t=11$ hours and $t=19$ hours from the start of the experiment (i.e., during tide 2), with sustained winds of greater than 9 $\mathrm{m} / \mathrm{s}$ (see Fig. 3c). Wind velocity reduced to a range of $4.5 \mathrm{~m} / \mathrm{s}-7 \mathrm{~m} / \mathrm{s}$ between hour 20 to hour 35, and to $4-6 \mathrm{~m} / \mathrm{s}$ between hour 40 and hour 50 . After the meteorological event, periods of moderate wind (3-5 m/s) occur between hour 50-52, hour 70-80, and hour 90-100.

Between $t=53$ hours and $t=88$ hours, wind was directed offshore (from north to south), as indicated by the dotted line.

A comparison of measured and predicted water levels show that winds caused a surge of $~$ $0.25 \mathrm{~m}$ by $t=20$ hours, and reached a maximum of $\sim 0.3 \mathrm{~m}$ at $t=30$ hours. Elevated water levels persisted through tide $4(0.2 \mathrm{~m}$ at High Water) and tide $5(0.06 \mathrm{~m}$ at High Water $)$ but became insignificant for tides 6-8. The surge coincided with seiching motions with velocities of $0-0.15 \mathrm{~m} / \mathrm{s}$ and a period of $\sim 500-1000$ seconds. These seiching motions occur primarily during tides $2-5$, and are shown by the envelope created by the 1-minute mean velocity (Fig. $3 \mathrm{~b}$ and Fig. $4 \mathrm{~b}$ ). As wind-setup disappears during tides 6-8, seiching motions become small.

Precipitation from the meteorological event increased the freshwater discharge in the subtidal creek, and began lowering salinity concentrations starting at $\sim t=17$ hours. During the meteorological event, large variation between bay water $(>20 \mathrm{psu})$ and fresher water $(<10$ $\mathrm{psu})$ were observed during wetting and drying. The effect of freshwater discharge was also observed at high water (HW), as salinity decreased from 25.8 psu during tide 1 to a minimum of 23.2 psu during tide 3 (Fig. 3d). After the meteorological event, the salinity at high water slowly increases, from 24.3 psu at $t=55$ hours to 26.1 psu at $t=92$ hours (figure $4 \mathrm{~d}$ ). Similarly, the differences in salinity over a tidal period lessen. 
As shown in Fig. 3e and Fig. 4e, the characteristic profile of suspended sediment concentration (SSC) over an immersed period includes a period of elevated sediment concentration during the flood, a reduction during the slack period, and a corresponding increase during the ebb (see figure $4 \mathrm{e}$ ). Overall, the tidally averaged concentration increases from $0.11 \mathrm{~kg} / \mathrm{m}^{3}$ during tide 1 to a peak of $0.19 \mathrm{~kg} / \mathrm{m}^{3}$ during tide 4 , then reduces to 0.02 $\mathrm{kg} / \mathrm{m}^{3}$ by tide 7 (post-event). The source of variation in SSC over the experiment is the focus of the next section.

The evolution of wave orbital velocity and energy over the experiment is depicted in Fig. 3c, Fig. 4c., and Fig. 5. The rms wave orbital velocity (estimated using an averaging time of 20 minutes after removing the 1 minute mean velocity), decreases from a maximum of $0.24 \mathrm{~m} / \mathrm{s}$ during the meteorological event to a maximum of $0.12 \mathrm{~m} / \mathrm{s}$ in tides $5-8$ (compare Fig. $3 \mathrm{c}$ and $4 c)$. Near-bed wave energy was typically smallest at high tide since orbital motions decay more with depth during periods of high water (for the same wave conditions).

Fig. 5 compares the power spectrum of velocity during the flood and ebb period of each tidal period. Three bands of energy are evident: locally forced wind waves between $0.25 \mathrm{~Hz}$ and 1 $\mathrm{Hz}$, offshore ocean swell between 0.05 and $0.15 \mathrm{~Hz}$, and intra-tidal motions between $3 \cdot 10^{-3}$ $\mathrm{Hz}$ and $8 \cdot 10^{-4} \mathrm{~Hz}$. Wind induced wave energy is largest during tide 2, and decreases in spectral energy and average period $(T=1 / f)$ occur as wind-forcing decreases in succeeding tides (see also Fig. 3c). After the flood of tide 5, no appreciable wind-wave energy is evident until the ebb of tide 8 . However, waves at the ocean swell frequency persist after local wind forcing vanishes (see also Talke \& Stacey, 2003), and are the largest component of wave forcing from the ebb of tide 5 through the flood of tide 7 . At lower frequencies, two peaks of energy are persistently found at periods of 500 seconds $\left(2 \cdot 10^{-3} \mathrm{~Hz}\right)$ and at $900-1000$ seconds. These intra-tidal motions, which we collectively call 'seiching', are largest during the windy periods from tide 1 through tide 5. Differences in energy between flood and ebb are characteristic for all energy bands, and are particularly well defined for tides 4,5 , and 8 (wind-waves), tide 5 and tide 7 (ocean swell) and tide 4, 7 and 8 (infra-tidal motions).

\subsection{Analysis of SSC on flat}

In this section we investigate whether wind causes the variation in waves and SSC at the experiment site by developing a regression between wind, wind-waves, and SSC (Fig. 6). Fig. $6 \mathrm{c}$ shows the least-squares fit to a scatter plot of the 1 hour mean wind energy and the 1 hour mean wind-wave energy. Because the fit of the line is good $\left(\mathrm{R}^{2}=0.78\right)$, our measurements indicate that on average, wave energy is linearly related to wind forcing. However, the scatter in the data indicates that other factors (such as spatial and temporal variation in the instantaneous wind field, changes to fetch, drag, and water depth and variation in ocean swell) influence the average hourly wave climate.

These factors produce a time history of wave climate that often deviates significantly from the linear relationship. As shown in Fig. 6a, a decrease in wind velocity from $98 \mathrm{~m}^{2} / \mathrm{s}^{2}$ to 76 $\mathrm{m}^{2} / \mathrm{s}^{2}$ between $t=13$ hours and $t=15$ hours $(\sim 23 \%$ decrease in energy) is correlated with a non-linear decrease in the 20 minute mean square wave energy from $0.051 \mathrm{~m}^{2} / \mathrm{s}^{2}$ to 0.028 $\mathrm{m}^{2} / \mathrm{s}^{2}$ (45\% decrease in energy). Similarly, between hour 20 and hour 21 the wind velocity measured at the Richmond Field station was halved from $9.3 \mathrm{~m} / \mathrm{s}$ to $4.7 \mathrm{~m} / \mathrm{s}$. This sudden change in wind forcing causes a corresponding decline in the 20 minute mean square energy of locally generated wind-waves from a maximum of $0.06 \mathrm{~m}^{2} / \mathrm{s}^{2}(\mathrm{rms}$ velocity of $0.24 \mathrm{~m} / \mathrm{s})$ to 
a maximum of $0.01 \mathrm{~m}^{2} / \mathrm{s}^{2}$ (rms velocity of $0.15 \mathrm{~m} / \mathrm{s}$ ) two hours later (figure 6a). Though a linear model (e.g. Fig. 6c) predicts a factor 4x decrease in wave energy, the actually measured wave energy decreases by a factor of $6 x$. This greater than expected decrease suggests that other factors affect wave heights (e.g., water depth or tidal flow), and that variability in the wind-field at periods of less than 1 hour may be important.

The sensitivity of wave energy to changes in wind climate is correspondingly reflected in the measured SSC (figure 6b). Increases in SSC concentration coincide with increases in wind energy (e.g., at $t=11$ hours and $t=19$ hours), while decreases in SSC correlate with decreases in wind energy (e.g., at $t=15$ hours and $t=30$ hours). During periods of onshore wind (data during the period of offshore wind from $t=55$ hours to $t=88$ hours are omitted), the correlation between hourly averaged wind wave energy and hourly averaged SSC is $R^{2}=$ 0.41. When selected periods of anomalous SSC are removed (hours 19-21, 35-41 and 89), the correlation is increased to $R^{2}=0.58$ and a reasonably linear trend is observed (see Fig. 6d).

The sensitivity of the regression in Fig. $6 \mathrm{~d}$ to omitting data and the scatter around the linear trend again points to the complexity and variability of the hydrodynamic forcing and sediment dynamics. However, because the correlation between tidal velocity and SSC is insignificant $\left(R^{2}=0.23\right)$, other processes besides wind-waves and tidal currents must control the variation of SSC (particularly during the times omitted in the analysis). These processes are the focus of the following sections (section 3.3 and 3.4).

Note that winds directed offshore (blowing from North to South) may also cause elevated SSC. For example, moderate offshore winds of 3-4 m/s during the ebb of tide 6 and flood of tide 7 produce negligible wind-wave energy (see Fig. 5) and hence no local erosion. However, the large SSC during the flood of tide 7 suggests that offshore wind is nonetheless important, as it likely produces waves and erosion in subtidal areas and results in a larger SSC signal than either the flood of tide 6 and tide 8, when offshore wind-forcing is much smaller (see Fig. 4). By contrast, offshore winds during the ebb of tide 6 do not cause any erosion upstream (shoreward) of the instruments, and no significant increase in SSC occurs. Note that tidal velocities are slightly larger during the flood of tide 7 than either the flood of tide 6 or tide $8(0.11 \mathrm{~m} / \mathrm{s}$ vs. $0.07-0.08 \mathrm{~m} / \mathrm{s})$, and may also contribute to differences in offshore erosion and advection during these flood tides. Finally, ocean swell forcing is larger during the flood of tide 7 than during either the ebb of tide 7 or tide 8 (see Fig. 5), and may also contribute to differences in SSC.

\subsection{Effect of Seiching on SSC}

To investigate the effect of seiching on SSC, we display the near bed 1-minute mean velocity and SSC between $t=36.5$ hours and $t=40.5$ hours in Fig. 7a and Fig. 7b. Variations in velocity and SSC at a period of 500-1000 seconds occur through-out this period, and serve to increase the longer term mean SSC (e.g., tidal mean). Interestingly, a persistent asymmetry occurs between SSC and the phase of the seiche, with the largest sediment concentrations generally occurring when the seiche velocity is shoreward (shaded dark). This is clearly observed in the scatter plot of the 1-minute mean velocity vs. the 1 minute mean SSC (Fig. $8 \mathrm{c}$ ) during this 4 hour span. For mean, near bed velocities less than $-0.05 \mathrm{~m} / \mathrm{s}$, near bed SSC is restricted to a narrow band around $0.1 \mathrm{~kg} / \mathrm{m}^{3}$. For velocities between $-0.05 \mathrm{~m} / \mathrm{s}$ and 0.15 $\mathrm{m} / \mathrm{s}$, SSCs trend upwards from $0.1 \mathrm{~kg} / \mathrm{m}^{3}$ to as much as $0.5 \mathrm{~kg} / \mathrm{m}^{3}$. 
300 Clearly, the stress exerted by the 1-minute mean flow cannot explain the observed sediment concentration, since a mean velocity of zero $\mathrm{m} / \mathrm{s}$ (mean stress $=0 \mathrm{~N} / \mathrm{m}^{2}$ ) results in larger sediment concentrations than an ebb velocity of $0.15 \mathrm{~m} / \mathrm{s}$. A possible explanation is that sediment is being resuspended by the ejection of sediment off of bedform ripples as the fluid reverses direction (e.g., Sleath \& Wallbridge, 2002). Variation in the frequency of ejection over a seiche would then produce the observed behaviour (Talke, 2005). Other explanations include settling lag effects or lateral interaction with turbid channel water.

\subsection{Frontal processes}

While elevated SSC is often correlated with local wave action (e.g., the range of times described in Fig. 6d, such as the flood of tide 5), examples of short duration ( 30 minutes), high concentration events that are decoupled from the local wind climate occur during the ebb of tide 2 and the flood of tide 4, 6, and 8 (see Fig. 3 and Fig. 4). Such pulses of SSC, termed the 'turbid tidal edge', are often observed on tidal flats (Dyer et al., 2000) and are attributed to local erosion from tidal currents (e.g., Pritchard \& Hogg, 2003). However, the small maximum tidal currents of $0.07 \mathrm{~m} / \mathrm{s}-0.11 \mathrm{~m} / \mathrm{s}$ during most of the experiment result in small shear stresses of $0.015 \mathrm{~N} / \mathrm{m}^{2}$ to $0.03 \mathrm{~N} / \mathrm{m}^{2}$ (using the quadratic friction law with a drag coefficient of 0.0025 , an order of magnitude often found in coastal environments (e.g., Green $\&$ McCave, 1995) and used in models (e.g., Roberts et al., 2000), which are unlikely to cause local erosion. Moreover, the large rise in SSC often occurs as wind energy decreases (e.g. ebb of tide 2 and flood of tide 4), and hence does not follow the linear relationship suggested between SSC and wind (Fig. 6). In the absence of wind forcing, the turbid tidal edge still occurs, despite the minimal local forcing (e.g., flood of tide 6 and tide 8).

A common feature of all the turbid pulses is that they coincide with sharp rises or falls in salinity. Using the approximation that $d s / d x \sim d s / d t / U$ (where $s=$ salinity and $U=$ tidal velocity), we estimate that the turbid pulse $\left(>0.9 \mathrm{~kg} / \mathrm{m}^{3}\right)$ and salinity decrease $(22.5 \mathrm{psu}$ to $\sim 1$ psu) between hour 20 and hour 21 coincides with salinity gradients of $\sim 40 \mathrm{psu} / \mathrm{km}$ and that the rise in turbidity (from $0.3 \mathrm{~kg} / \mathrm{m}^{3}$ to $0.52 \mathrm{~kg} / \mathrm{m}^{3}$ ) and salinity $(+9.4 \mathrm{psu}$ ) at $t=26.25$ hours over a 2 minute span implies a local gradient of $\sim 800 \mathrm{psu} / \mathrm{km}$. During the calmer periods of tide 6 and tide 8 , gradients of $\sim 0.030 \mathrm{psu} / \mathrm{m}$ and $0.01 \mathrm{psu} / \mathrm{m}$ are advected past the sensors and coincide with a factor $\sim 5 \mathrm{x}$ increase in SSC (peak of $0.13 \mathrm{~kg} / \mathrm{m}^{3}$ and $0.2 \mathrm{~kg} / \mathrm{m}^{3}$, respectively). Salinity gradients are larger during the flood, and are consistent with values observed in the nearby subtidal channel by Ralston and Stacey (2005).

The sharp variations in sediment concentration and salinity observed during ebbing and flooding periods suggests that a front influenced by freshwater runoff is moving past the sensors. The pulse of SSC observed during the ebb of tide 2 and the flood of tide 3, tide 4, tide 6 , and tide 8 is consistent with a turbidity maximum formed at the interface of two bodies of water in which longitudinal mixing is suppressed by strong horizontal density gradients. This mechanism is described for the nearby channels by Ralston and Stacey (2005), and our data suggests this process also occurs on the adjoining flats. The SSC in a front likely consists of sediment eroded non-locally during the previous tidal period or at offshore (more energetic) locations, and held in suspension by settling lag and turbulence effects (Ralston \& Stacey, 2007). Frontal processes govern the formation, dispersion, and time scale of the pulses of SSC. While Ralston and Stacey $(2005,2007)$ describe a process occurring primarily during flood tides after Low-Low-Water (LLW), our data suggests frontal processes can occur during the ebb (e.g., tide 2) and after High-Low-Water (HLW) given sufficient freshwater discharge (e.g., tide 6). 


\subsection{Sediment fluxes}

In this section we investigate the sediment flux occurring over a tide at different time scales. Combining the effect of locally driven wind waves and ocean swell together, we split the measured velocity $V(t)$ and sediment concentration $C(t)$ into wave, seiche, tidal, and residual (tidally averaged) components,

$$
C=C_{\text {residual }}+C_{\text {tide }}+C_{\text {seiche }}+C_{\text {wave }},
$$

$V=V_{\text {residual }}+V_{\text {tide }}+V_{\text {seiche }}+V_{\text {wave }}$.

Velocity is decomposed along the North-South axis, which corresponds to the down-slope direction and the primary direction of both wave and tidal forcing. Using the function $f$ for either the measured sediment concentration, $C$, or velocity, $V$, we decompose the measured signal using bin-averages over the time scales $T, N$, and $M$,

$f_{\text {residual }}=\frac{1}{T} \sum_{t=0}^{t=T} f(t) \Delta t$

$$
\left.f_{\text {seiche }}(t)\right|_{t=j(M-1)} ^{t=j M-\Delta t}=\frac{1}{M} \sum_{t=j(M-1)}^{t=j M}\left(f(t)-f_{\text {residual }}-f_{\text {tidal }}\right) \Delta t, \quad j=1,2, \ldots . ., T / M
$$

The time increment $\Delta t$ is the sampling period of $1 / 8$ second. These decompositions result in histograms of velocity and SSC with time increments of $T, N$, or $M$ (Eqs. 3, 4, and 5, respectively). The residual time scale for an intertidal flat is the time of immersion, $T$, which we estimate as an integer number of 10 minute measurement bursts. We define the tidally varying time scale $N$ to be 1800 seconds (30 minutes), and the variability of the seiche scale $M$ to be 60 seconds ( 1 minute). These time scales correspond to periods of low energy in the power spectrum of velocity, as defined by the frequencies $1 / 1800 \mathrm{~Hz}$ and $1 / 60 \mathrm{~Hz}$ in figure 5 . While some unsteadiness from lower frequencies is contained in higher frequency components, (e.g., the tidal signal varies somewhat over 30 minutes and enters $f_{\text {seiche }}$ ), this variability is small compared to the higher frequency variability (e.g., the seiche). Note that the number $T / N$ is rounded up to the nearest integer. When $T / N$ is not an integer number, the averaging time of the last bin is defined by the time period of the remainder. In practice, this means that $N$ is equal to 10 or 20 minutes for the last bin in some tidal periods, and may result in some truncation of the seiche signal.

Assuming that diffusive fluxes are small, the average sediment flux $\Phi_{S S C}=\frac{1}{T} \int_{0}^{T} C V d t$ over a period of immersion $T$ at one point in the water column is then: 


$$
\Phi_{\text {SSC }}=\frac{1}{T} \int_{0}^{T}\left(C_{\text {wave }} V_{\text {wave }}+C_{\text {seiche }} V_{\text {seiche }}+C_{\text {tidal }} V_{\text {tidal }}+C_{\text {residual }} V_{\text {residual }}+\Phi_{\text {cross-terms }}\right) d t
$$

The cross-terms are extremely small when integrated over the time period $T$, and are typically less than $10^{-12} \mathrm{~kg} \mathrm{~m}^{-2} \mathrm{~s}^{-1}$ (see the electronic supplement for additional discussion).

The sediment fluxes occurring during tides 1-4 and tides 5-8 are shown in Fig. 8a and Fig 8b. Positive values of flux denote onshore transport, while differences in $y$-axis scaling between Fig. $6 \mathrm{a}$ and Fig. $6 \mathrm{~b}$ reflect the order of magnitude larger fluxes during tides 1-4. The tidallyaveraged, residual flux of sediment $\left(\frac{1}{T} \int_{0}^{T} C_{\text {residual }} V_{\text {residual }} d t\right)$ is directed offshore during tides 1-4 (average of $-5.4 \cdot 10^{-3} \mathrm{~kg} / \mathrm{m}^{2} / \mathrm{s}$ ) but nearly vanishes during tides $5-8\left(6.5 \cdot 10^{-6} \mathrm{~kg} / \mathrm{m}^{2} / \mathrm{s}\right.$ ). Flux from tidally varying processes, $\frac{1}{T} \int_{0}^{T} C_{\text {tidal }} V_{\text {tidal }} d t$, is offshore during tides 1-4 (average of $\left.4.0 \cdot 10^{-4} \mathrm{~kg} / \mathrm{m}^{2} / \mathrm{s}\right)$ and onto the flat for tides $5-8\left(5.5 \cdot 10^{-4} \mathrm{~kg} / \mathrm{m}^{2} / \mathrm{s}\right)$. The flux of SSC at the seiching frequency, $\frac{1}{T} \int_{0}^{T} C_{\text {seiche }} V_{\text {seiche }} d t$, is always directed onshore, and accounts for 14 percent of the total flux during tides $1-4$, but less than $1 \%$ of the flux during tides 5-8. Fluxes at the wave frequency $(<1 / 60 \mathrm{~Hz})$ are small but non-negligible during tides 3-4. Because no coherence is observed in the optical backscatter signal at wind-wave frequencies, these fluxes may reflect transport due to lower frequency variability such as ocean swell or wind-wave groups.

Overall, tidally-averaged, residual processes dominate net export of sediment during the meteorological event of tides 1-4 (i.e., $\left.\int_{0}^{T} C V d t<0\right)$ and tidally varying processes produce onshore flux during the calmer period of tides 5-8 (i.e., $\int_{0}^{T} C V d t>0$ ). Offshore sediment fluxes during the meteorological event (tides 1-4) are an order of magnitude larger than the onshore fluxes during the calmer period immediately afterwards (tides 5-8).

\section{Discussion}

In this section we discuss the physical mechanisms that produce fluxes during both the meteorological event and afterwards.

\subsection{Residual, tidally averaged fluxes}

The dominance of tidally-averaged, residual fluxes during tides 1-4 is caused by order of magnitude increase in $C_{\text {residual }}$ and $V_{\text {residual }}$ above non-event conditions (e.g., tides 5-8). Fig. 9 shows that during the meteorological event, residual flow off the flat increases from $\sim-0.01$ $\mathrm{m} / \mathrm{s}$ at the beginning of the meteorological event (tide 1 ) to a maximum of $-0.075 \mathrm{~m} / \mathrm{s} \mathrm{during}$ tide 2. By comparison, the tidally-averaged velocities after the meteorological event vary from $0.001-0.008 \mathrm{~m} / \mathrm{s}$. Similarly, tidally averaged sediment concentrations during the meteorological event $\left(0.11-0.19 \mathrm{~kg} / \mathrm{m}^{3}\right)$ are much larger than sediment concentrations 
afterwards $\left(0.02-0.05 \mathrm{~kg} / \mathrm{m}^{3}\right)$. The combination of elevated sediment concentrations and increased residual flows causes large fluxes of sediment off the flat, particularly for tides 2,3 , and 4. During the calm period after the meteorological event, tidally averaged fluxes are correspondingly decreased; moreover, because the direction of flux is positive during tide 5 and tide 7 but negative during tide 6 and tide 8 , the integrated net flux over the post-event period is further reduced.

During the meteorological event between April $11^{\text {th }}$ and April $13^{\text {th }}$, many factors may work together to create the residual flow pattern. The large salinity variations observed during this time period (see Fig. 3) indicate an influence of freshwater runoff from the local water shed. Wind stress also produces circulation patterns, as evidenced by water level set-up and its release during tides $1-5$. The large salinity gradients likely drive gravitational circulation, which was found by Ralston and Stacey (2005) to produce a near-bottom inflow on the order of $0.01-0.02 \mathrm{~m} / \mathrm{s}$ over the shoal of our experimental site. Finally, the diurnal inequality in water level that occurs during tides 1-4 results in residual, tidally averaged currents.

The tidally averaged increase in SSC during tides 1-4 is primarily a result of the increased wave forcing, as suggested by the regressions in Fig. 6. However, seiching motions also appear to drive increases in tidally averaged SSC (see section 3.3). The more rigorous mixing during periods of large wind-waves also keeps sediments in suspension during slack tides, hence reducing the deposition (removal) of sediments. Combined with the offshore flow of water near the bed, sediment is exported from the flat to deeper offshore waters.

\subsection{Tidal Time Scale}

Sediment flux due to tidally varying processes is controlled by asymmetries in SSC and velocity over a tidal period. We investigate the factors influencing net flux at the tidal time scale by decomposing the SSC and velocity measurements into symmetric and asymmetric components

$$
C_{\text {tidal }}=C_{\text {base }}+C^{\prime}
$$

$$
V_{\text {tidal }}=V_{\text {base }}+V^{\prime}
$$

where $C_{\text {base }}$ is an even (symmetric) function and $V_{\text {base }}$ is an odd function with respect to the midpoint of the period of immersion (T/2), and $C^{\prime}$ and $V^{\prime}$ are deviations from the symmetrical function over the tidal period. Using our data, we define the even component of SSC around $T / 2$ as follows:

$$
C_{\text {base }}(t)=C_{\text {tidal }}(t), t<T / 2
$$

$$
C_{\text {base }}(t)=C_{\text {tidal }}(T-t), t>T / 2
$$

The odd component of velocity is defined similarly:

$$
V_{\text {base }}(t)=V_{\text {tidal }}(t), \mathrm{t}<T / 2
$$

$$
V_{\text {base }}(t)=-V_{\text {tidal }}(T-t), \quad t>T / 2
$$


481

482

483

484

485

486

487

488

489

490

491

492

493

494

495

496

497

498

499

500

501

502

503

504

505

506

507

508

509

510

511

512

513

514

515

516

517

518

519

520

521

522

523

Using these definitions, we find that the tidally integrated flux of SSC at the tidal time scale can be rewritten as,

$$
\frac{1}{T} \int_{o}^{T} C_{\text {tidal }} V_{\text {tidal }} d t=\underbrace{\frac{1}{T} \int_{0}^{T} C_{\text {tidal }} V^{\prime} d t}_{\Phi_{v^{\prime}}}+\underbrace{\frac{1}{T} \int_{0}^{T} V_{\text {base }} C^{\prime} d t}_{\Phi_{C^{\prime}}},
$$

where we have used the observation that the integral of the product of even and odd functions vanishes over the time period $T$, i.e., $\int_{0}^{T}\left(C_{\text {base }} V_{\text {base }}\right) d t=0$. Hence, asymmetries in velocity $\left(V^{\prime}\right)$ and SSC ( $C^{\prime}$ ) over a tidal period are required to produce sediment fluxes $\Phi_{V^{\prime}}$ and $\Phi_{C^{\prime}}$, respectively (see Eq. 11).

Fig. 10 shows the magnitude of the sediment fluxes $\Phi_{V^{\prime}}$ and $\Phi_{C^{\prime}}$ over tides 1-8. During tides 1-3, both components of flux are on the same order of magnitude. By contrast, the $\Phi_{V^{\prime}}$ term nearly vanishes during tides 5-8 and the tidally varying fluxes are dominated by asymmetries in SSC between the flood and the ebb.

To understand why the shift to $\Phi_{C^{\prime}}$ dominance occurs in tides 5-8, we investigate the tidal variation of SSC (Fig. 11a and Fig. 12a), velocity (Fig. 11b and 12b) and the product $C_{\text {tidal }} V_{\text {tidal }}$ (Fig. 11c and Fig. 12c) during tides 1-4 (Fig. 11) and tides 5-8 (Fig. 12). Onshore velocity and sediment flux are shaded dark and defined as (+), whereas offshore sediment flux and velocity are shaded light and defined as (-). Similarly, positive deviations from the tidal averaged SSC are shaded dark (+) and negative deviations are shaded light and defined as (-) (see Eq. 5). The function $C_{\text {base }}$ is depicted in Fig. 11a and Fig. 12a and the function $V_{\text {base }}$ is depicted in Fig. $11 b$ and Fig. 12b.

During the meteorological event, both SSC and velocity are quite asymmetric, as can be observed by the differences between the measured tidal variation $\left(C_{\text {tidal }}\right.$ and $\left.V_{\text {tidal }}\right)$ and the hypothetical symmetric functions $C_{\text {base }}$ and $V_{\text {base }}$. While SSC remains asymmetric over a tidal period during tides 5-8, the flow velocity is relatively symmetric (as shown by the relatively good agreement between $V_{\text {base }}$ and $\left.V_{\text {tidal }}\right)$.

\subsubsection{Factors producing asymmetry}

The asymmetric tidal variation in flow velocity during the meteorological event, $V^{\prime}$, is caused both by the diurnal inequality in tides and by events such as freshwater discharge and wind induced circulation and setup/set-down. For example, the diurnal inequality results in small tidal currents during the ebb of tide 1 and flood of tide 2 , and contributes to an onshore $\Phi_{V^{\prime}}$ during tide 1 and an offshore $\Phi_{V^{\prime}}$ during tide 2 (see Fig. 10). The setup caused by wind also appears to prolong the flood tide during tide 2 . Finally, the coincidence of freshwater discharge (as evidenced by salinity concentrations $<10 \mathrm{psu}$ ) and the release of water set-up due to decreasing wind at hour 20 cause large ebb currents. As the diurnal inequality diminishes and the freshwater discharge and setup disappear (particularly after tide 5), the asymmetric velocity profile becomes unimportant to the flux balance. Hence, unlike 
modelling studies suggest (e.g., Ridderinkhof, 1998), asymmetries in velocity caused by overtides (e.g., the $\mathrm{M}_{4}$ tide) do not appear to be important for fluxes at our site.

Two primary forcing mechanisms produce asymmetries of SSC over a tidal cycle at our site: The turbid tidal edge (mediated by frontal processes) and the tidal variation in wind forcing. In the absence of significant wind or wave activity (e.g., tide 6), the baseline asymmetry in SSC is characterized by higher concentrations on flood tides than on ebbs due to the turbid tidal front. These frontal pulses of turbidity are associated with strong salinity gradients, occur over a short time scale ( $<1$ hour), and are usually largest during the flood tide (see section 3.4). Variations in wind forcing cause tidal variations in wind-wave energy and seiching (see Fig. 5) over time scales greater than an hour, and hence alter SSC (see section 3.2 and 3.3).

The tidal asymmetry in SSC due to wind forcing is most clearly observed by comparing tide 5 and tide 8 . During the flood of tide 5 , wind-driven waves produce a peak concentration of $\sim 0.2 \mathrm{~kg} / \mathrm{m}^{3}$ above the tidal mean, which reduces over 1.5 hours as wind forcing subsides (see Figs. 4 and 12). Because wind-wave energy is negligible during the ebb (see Fig. 5), SSC does not increase much and a flood dominated SSC asymmetry (and onshore sediment flux) occurs. By contrast, wind energy and wave energy are small during the flood of tide 8 , but increase during the ebb (see Fig. 4 and Fig. 5). As a result, SSC shifts above the tidal average for 1.5 hours during the ebb of tide 8 , producing a net offshore flux.

The effect of variable wind-forcing on asymmetries in SSC is not solely tied to local variations in wind-driven waves. For example, seiching motions are much larger during the flood of tide 4 than during the ebb, likely due to the decrease in wind forcing (and release of setup) that occurs after hour 33 (see Fig. 3 and Fig. 5). These seiching motions not only increase the magnitude of SSC at the seiche frequency (see Fig. 7), but also increase the tidally varying SSC (e.g., between hour 38-40 in Fig. 11). Similarly, the decrease in wind during the ebb of tide 2 is correlated with large ebb currents that can erode sediment. Offshore (southwards directed) wind may stir offshore, subtidal sediments (through wave action) which are transported shoreward during the flood, and cause a flood dominated asymmetry in SSC over a tidal period (e.g. tide 7; see section 3.2). Finally, ocean swell forcing is larger during the ebb of tide 5 and the flood of tide 7 than the corresponding flood and ebb, respectively, and may also contribute to asymmetries in SSC.

\subsubsection{Effects of Phasing and Time Scales}

The net effect of asymmetries in velocity $\left(V^{\prime}\right)$ and SSC $\left(C^{\prime}\right)$ depends on their relative phasing with $C_{\text {tidal }}$ and $V_{\text {base }}$ and on their respective magnitudes and time-scales of variation. Instantaneous fluxes of SSC at the tidal time scale are maximized when large SSC is correlated with large advective velocities. As shown in Fig. 11 and Fig. 12, examples of such events are found during the ebb of tide 2 (hour 20) and the flood of tide 1 (hour 2) and 5 (hour 51-53). Much smaller fluxes, however, occur when large SSC corresponds with small tidal velocities (e.g., hour 35), or when maximum tidal velocities occur at small SSC (hour 70 or hour 84).

Because of differing time scales and timing, turbid tidal fronts and wave induced turbidity events interact differently with $V_{\text {base }}$ in Eq. 11 . Turbid pulses during the flood are often higher in magnitude than the corresponding increase in SSC during the ebb (see tide 6 and tide 8 in Fig. 12), and drive onshore flux in calm conditions (e.g. tide 6). However, the time-scale over 
which the turbid pulse acts is small ( 30 minutes) compared to wave induced turbidity events, which generally occur over time periods of greater than 1 hour (see flood of tide 5 and ebb of tide 8, for example). Hence, fluxes from the relatively small SSC during the ebb of tide 8 (Fig. 12), which is integrated over 1.5 hours, outweighs the short but intense turbidity front which is integrated over 30 minutes. The effect of the differing time scales is amplified by the timing of the front and the wind event. The front during the flood of tide 8 occurs at a non-peak flood velocity $(0.053 \mathrm{~m} / \mathrm{s}$ vs. $0.083 \mathrm{~m} / \mathrm{s}$ at the maximum), while the much smaller maximum SSC during the ebb of $0.08 \mathrm{~kg} / \mathrm{m}^{3}$ occurs at the nearly the maximum ebb velocity $(0.081 \mathrm{~m} / \mathrm{s})$. Because wind-events are longer, they are more likely to coincide with the maximum tidal velocity and therefore produce large sediment fluxes.

\subsection{Time Scales of Wind and Swell}

As observed in the previous section, the timing of wind events relative to the phase of the tide modifies the net flux onto or off of the flat. Two basic conditions may occur. First, the wind wave event may last over the entire tidal period, as occurs during most of tide 2 during the meteorological event. On the other extreme, wind events may occur entirely during the flood (tide 5) or during the ebb (tide 8). To understand the likelihood that a wind event will be biased towards either the flood or ebb, we analyze wind data from the Richmond Field Station for the years 1999-2005. We define an event to be the time period over which sustained winds are greater than $5 \mathrm{~m} / \mathrm{s}$, which is a standard deviation from the long term mean of 3.2 $\mathrm{m} / \mathrm{s}$ and is also the order of magnitude for which sediment resuspension occurs on other intertidal flats (de Jonge and van Beusekom, 1995, Christie et al., 1999, Dyer et al. 2000). Two events that are separated by only 1 hour are combined into one event period, to allow for randomness in the wind field during a contiguous event. For comparison, we also analyze the significant wave height (average of top 1/3 measured wave amplitudes per hour) measured at an offshore buoy (NDBC buoy 46026) for an estimate of offshore swell. Again, we define an event as a standard deviation from the average, which is $2.8 \mathrm{~m}$ (mean significant wave height $=2.0 \mathrm{~m}$ ). Though ocean swell rarely dominates the energy budget at this site, Fig. 5 shows that ocean swell provides an important contribution to the total forcing. Thus, the time scales of ocean swell provide an interesting contrast to locally driven wind waves.

Results in Fig. 13 show that the most likely time scale of both a wind event and ocean swell event is 1 hour (26\% and $28 \%$, respectively). Thus, as confirmed by the spectral analysis of velocity (see Fig 5), both ocean swell and wind waves are highly likely to occur over only a portion of the tide: $\sim 51 \%$ of wind events are 3 hours or less, while $\sim 54 \%$ of offshore swell events are 5 hours or less. Indeed, $90 \%$ of wind events have a time period of less than 12 hours, the time scale of a tide. By contrast, $28 \%$ of offshore swell events exceed the time scale of a tidal period.

The frequency distribution of wind and ocean swell events suggests that the strong dependence of tidally integrated sediment flux to variations in wind and waves are a longterm characteristic of this intertidal flat, and not just an artefact of this experiment. Changes in wind forcing and hence sediment flux are observed both within a tidal phase (e.g., during the ebb of tide 2 between hour 20 and 21) and between tidal phases (e.g., the flood and ebb of tide 5 or tide 8 ). As a result, the phasing and duration of wind and wave events relative to the local tidal forcing is an important factor in the net sediment flux. Hence, the assumption that wind forcing is constant over a tidal period in models of sediment transport (e.g., Ridderinkhof, 1998, Roberts et al., 2000, Waeles et al., 2004), may need to be examined. 


\section{Conclusions}

Field observations of hydrographic parameters and sediment concentration on an intertidal flat show that multiple frequencies of forcing contribute to the flow field, including locally driven wind-waves, ocean swell, intra-tidal seiching motions (500-1000 second period), tidal flows, and sub-tidal variation such as freshwater discharge. Because the median time scale of wind and swell events is small (3 hours and 5 hours, respectively), wave and seiching motions (and hence SSC) are often asymmetrically distributed between ebb and flood. Precipitation from a meteorological event leads to freshening and the formation of a sharp salinity front that is advected past the sensors during the flood and ebb. Sediment is trapped at the salinity front, and is observed at the sensors as a short ( 30 minutes) but intense increase in SSC.

Sediment is exported during a meteorological event primarily due to wind driven and freshwater forcing. Tidally averaged fluxes of SSC dominate and are marked by an order of magnitude increase in both the residual circulation (offshore) and tidally-averaged sediment concentration. The enhanced residual circulation is likely driven by wind and freshwater forcing, while increases in SSC are primarily driven by local wind-waves and seiching. Tidally varying processes (such as wind forcing and frontal dynamics) either amplify (tide 2) or diminish (tide 4) the net sediment fluxes during the meteorological event by producing asymmetries in both the tidal velocity and the tidal profile of SSC. Net sediment fluxes at the seiche frequency are always onshore due to a bias in SSC with respect to the seiche period, and occur primarily during the meteorological event.

After the meteorological event, both tidally averaged wind and freshwater forcing relax and the dominant contribution to sediment flux is made by tidally varying processes. In particular, the flood tide is marked by elevated turbid fronts, both from onshore wind (tide 5), offshore wind (tide 7) and salinity driven frontal processes (tide 6 and tide 8). By contrast, salinity decreases more gradually during the ebb and little erosion or trapping of SSC occurs. As a result of this asymmetry in SSC, sediment flux is generally onshore. However, moderate onshore wind of 3-4 m/s during an ebb period (e.g., tide 8 ) is capable of producing significant increases to SSC and reversing the net sediment flux.

To conclude, sediment fluxes at an intertidal flat are controlled by periodic tidal forcing and by event driven processes such as wind and freshwater discharge. The shifting influence of wind and freshwater discharge over a period of days produces large, tidally averaged fluxes during a meteorological event and produces the asymmetries necessary for sediment transport at a tidal frequency. Over the time period considered, the phasing and duration of wind events and freshwater discharge relative to the local tidal forcing greatly affect net sediment flux.

\section{Acknowledgements}

Many thanks to David Ralston, Jon Fram, Deanna Sereno, Seungjin Baek, Shitao Xu, Kate Hucklebridge, Josh Sharp, and Kurt Talke for logistical support during the experiment. The research was funded by National Institutes of Health grant number P42ES0475 from the National Institute of Environmental Health Sciences, and was completed with the funding of LOICZ project 014.27.013 (Land Ocean Interaction in the Coastal Zone, funded by NWOALW, the Netherlands Organization for Scientific Research). The authors thank the anonymous reviewers for their helpful and constructive criticism. 
674

675

676

677

678

679

680

681

682

683

684

685

686

687

688

689

690

691

692

693

694

695

696

697

698

699

700

701

702

703

704

705

706

707

708

709

710

711

712

713

714

715

716

717

718

719

720

721

722

\section{References}

Andersen, T.J., M. Pejrup, 2001. Suspended sediment transport on a temperate, microtidal mudflat, the Danish Wadden Sea. Marine Geology, 173, 69-85.

Bassoullet, P., Hir, P.L., Gouleau, D., Robert, S., 2000. Sediment transport over an intertidal mudflat: Field investigations and estimation of fluxes within the 'Baie de Marennes-Oleron' (France). Continental Shelf Research, 20, 1635-1653.

Black, K.S., 1998. Suspended Sediment Dynamics and Bed Erosion in the High Shore Mudflat Region of the Humber Estuary, UK. Marine Pollution Bulletin, 37, Nos. 3-7, 122133.

Christiansen, C., Vølund, G., Lund-Hansen, L.C., \& J. Bartholdy, 2006. Wind influence on tidal flat sediment dynamics: Field investigations in the Ho Bugt, Danish Wadden Sea. Marine Geology 235, 75-86.

Christie, M.C., Dyer, K.R., Turner, P., 1999. Sediment Flux and Bed Level Measurements from a Macro Tidal Mudflat, Estuarine, Coastal and Shelf Science 49, 667-688.

de Haas, H., Eisma, D., 1993. Suspended-Sediment Transport in the Dollard Estuary, Netherlands Journal of Sea Research, 31 (1), 37-42.

de Jonge,V.N. , van Beusekom, J.E.E. , 1995. Wind and tide induced resuspension of sediment and microphytobenthos from tidal flats in the Ems estuary. Limnol. Oceanogr. 40: 766-778.

Dyer, K. R., 1998. The typology of intertidal mudflats. Black, K.S., Patterson, D.M., and Cramp, A. (eds.), Sedimentary Processes in the Intertidal Zone. Geological Society, London, Special Publications, 139, 11-24.

Dyer, K.R., Christie, M.C., Feates, N., Fennessy, M.J., Pejrup, M., and van der Lee, W., 2000. An Investigation into Processes Influencing the Morphodynamics of an Intertidal Mudflat, the Dollard Estuary, The Netherlands: I. Hydrodynamics and Suspended Sediment. Estuarine, Coastal and Shelf Science, 50, 607-625.

Friedrichs, C.T., Aubrey, D.G. 1996 Uniform bottom shear stress and equilibrium hypsometry of intertidal flats. In Mixing in Estuaries and Coastal Seas (ed. C. Pattiaratchi), Volume 50 of Coastal and Estuarine Studies, pp. 405-429. American Geophysical Union.

Green, M.O., McCave, I.N. ,1995. Seabed drag coefficient under tidal currents in the eastern Irish Sea, Journal of Geophysical Research, 100, C8, 16057-16070.

Janssen-Stelder, B., 2000. The effect of different hydrodynamic conditions on the morphodynamics of a tidal mudflat in the Dutch Wadden Sea. Continental Shelf Research 20, 1461-1478.

Kirby, R., 2000. Practical implications of tidal flat shape, Continental Shelf Research, 20, 1061-1077. 
Kornman, B.A. ,De Deckere, E.M.G.T., 1998. Temporal variation in sediment erodibility and suspended sediment dynamics in the Dollard estuary. In: Black, K.S., Paterson, D.M. and Cramp, A. (eds.) Sedimentary Processes in the Intertidal Zone. Geological Society, London, Special Publications, 139, 231-241.

Le Hir, P., Roberts, W., Cazaillet, O., Christie, M., Bassoullet,P., Bacher, C., 2000.

Characterization of intertidal flat hydrodynamics. Continental Shelf Research, 20, 14331459.

O’Brien, D.J., Whitehouse, R.J.S., Cramp, A., 2000. The cyclic development of a macrotidal mudflat on varying timescales. Continental Shelf Research 20, 1593-1619.

Pritchard, D., Hogg, A.J., Roberts, W., 2002. Morphological modelling of intertidal mudflats: the role of cross-shore tidal currents. Continental Shelf Research, 22, 1887-1895.

Pritchard, D., \& A.J. Hogg, 2003. Cross-shore sediment transport and the equilibrium morphology of mudflats under tidal currents. Journal of Geophysical Research, 108, C10, 3313, doi:10.129/2002JC001570.

Ridderinkhof, H. 1998. On the sensitivity of the large scale transport and distribution of fine grained sediments in a tidal basin to the formulation of the erosion-sedimentation cycle. In Physics of Estuaries and Coastal Seas (eds. J. Dronkers \& M. Sheffers), 145-153. Balkema.

Ridderinkhof, H., Van der Ham., R., van der Lee, W., 2000. Temporal variations in concentration and transport of suspended sediments in a channel-flat system in the EmsDollard estuary. Continental Shelf Research 20, 1479-1493.

Ralston, D.K., 2005. Hydrodynamics and scalar transport in subtidal channels through intertidal mudflats. PhD Thesis, University of California, Berkeley.

Ralston, D.K., Stacey, M.T., 2005. Longitudinal dispersion and lateral circulation in the intertidal zone. Journal of Geophysical Research-Oceans 110, C07015, 17 pp.

Ralston, D.K., Stacey, M.T., 2007. Tidal and meteorological forcing of sediment transport in tributary mudflat channels. Continental Shelf Research, 27, 1510-1527.

Roberts, W. , Le Hir, P., Whitehouse, R.J.S., 2000. Investigation using simple mathematical models of the effect of tidal currents and waves on the profile shape of intertidal mudflats. Continental Shelf Research 20, 1079-1097.

Shi, Z., Chen, J.Y., 1996. Morphodynamics and sediment dynamics on intertidal mudflats in China (1961-1994). Continental Shelf Research, 16, No. 15, 1909-1926.

Sleath, J.F.A., Wallbridge, S., 2002. Pickup from Rippled Beds in Oscillatory Flow. Journal of Waterway, Port, Coastal and Ocean Engineering, 128, 6, 228-237.

Staats, N., de Deckere, E., Kornman, B., van der Lee, W., Termaat, R., Terwindt, J., de Winder,B., 2001. Observations on suspended particulate matter (SPM) and microalgae in the Dollard estuary, the Netherlands: Importance of late winter ice cover of the intertidal flats. Estuarine, Coastal, and Shelf Science, 53 (3) 297-306. 
Talke, S.A., 2005. An Investigation on the Hydrodynamics and Sediment Dynamics on an Intertidal Mudflat on Central San Francisco Bay. PhD Thesis, University of California, Berkeley.

Talke, S.A., Stacey, M.T., 2003. The influence of oceanic swell on flows over an estuarine intertidal mudflat in San Francisco Bay, Estuarine, Coastal, and Shelf Science 58, 541-554.

Waeles, B., Le Hir, P., Jacinto, R. S. 2004 Modélisation morphodynamique cross-shore d'un estran vaseux. Comptes Rendus Geoscience 336, 1025-1033.

Wright, S.A., Schoellhamer, D.H., 2004. Trends in the sediment yield of the Sacramento River, California, 1957-2001. San Francisco Estuary and Watershed Science [online serial]. 2, Issue 2, Article 2.

Yang, S.L., Friedrichs, C., Zhong, S., Ping-Xing, D., Zhu, J., Zhao, Q.Y., 2003.

Morphological Response of Tidal Marshes, Flats, and Channels of the Outer Yangtze River Mouth to a Major Storm. Estuaries, 26, 1416-1425.

\section{Figures}

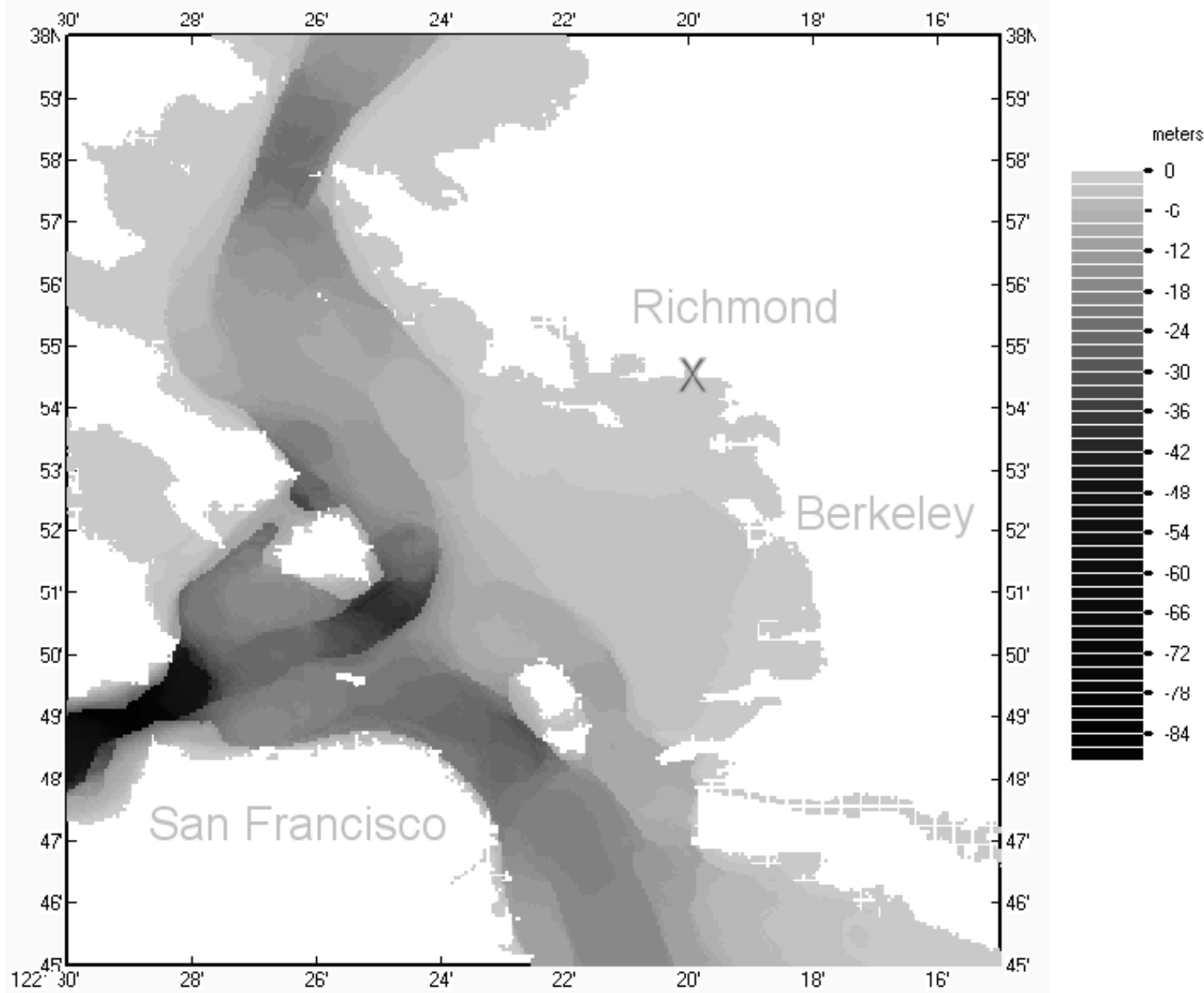

Figure 1-a: Location map of experiment in terms of latitude and longitude. The location of the experiment is marked with an ' $\mathrm{X}$ '. 


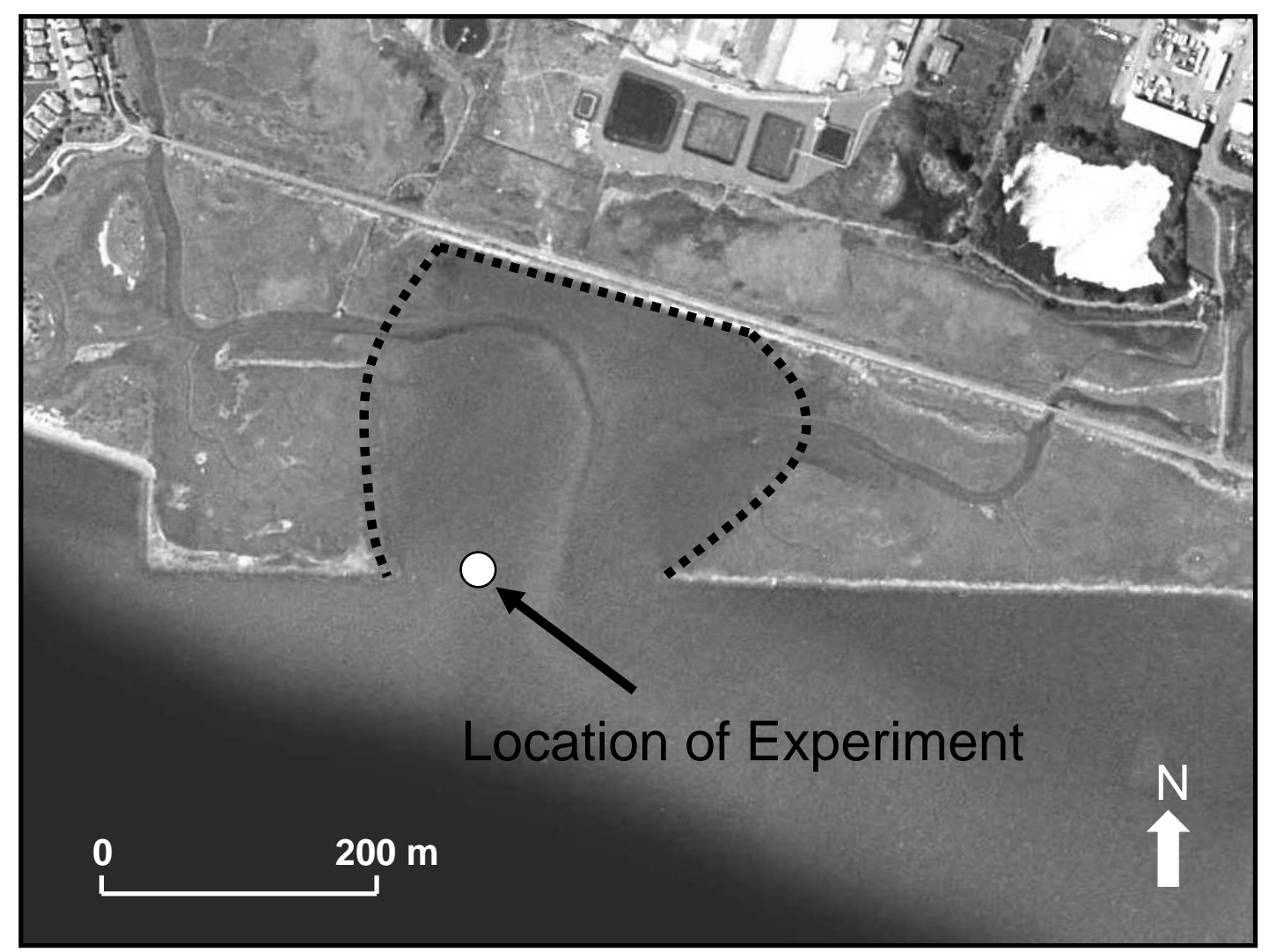

Figure 1b: Location of the instrument frame on the intertidal mudflat near the Richmond 800 Field Station. The approximate borders of the mudflat with the intertidal marsh and the multi801 use trail on the north side are denoted by the dotted line. 


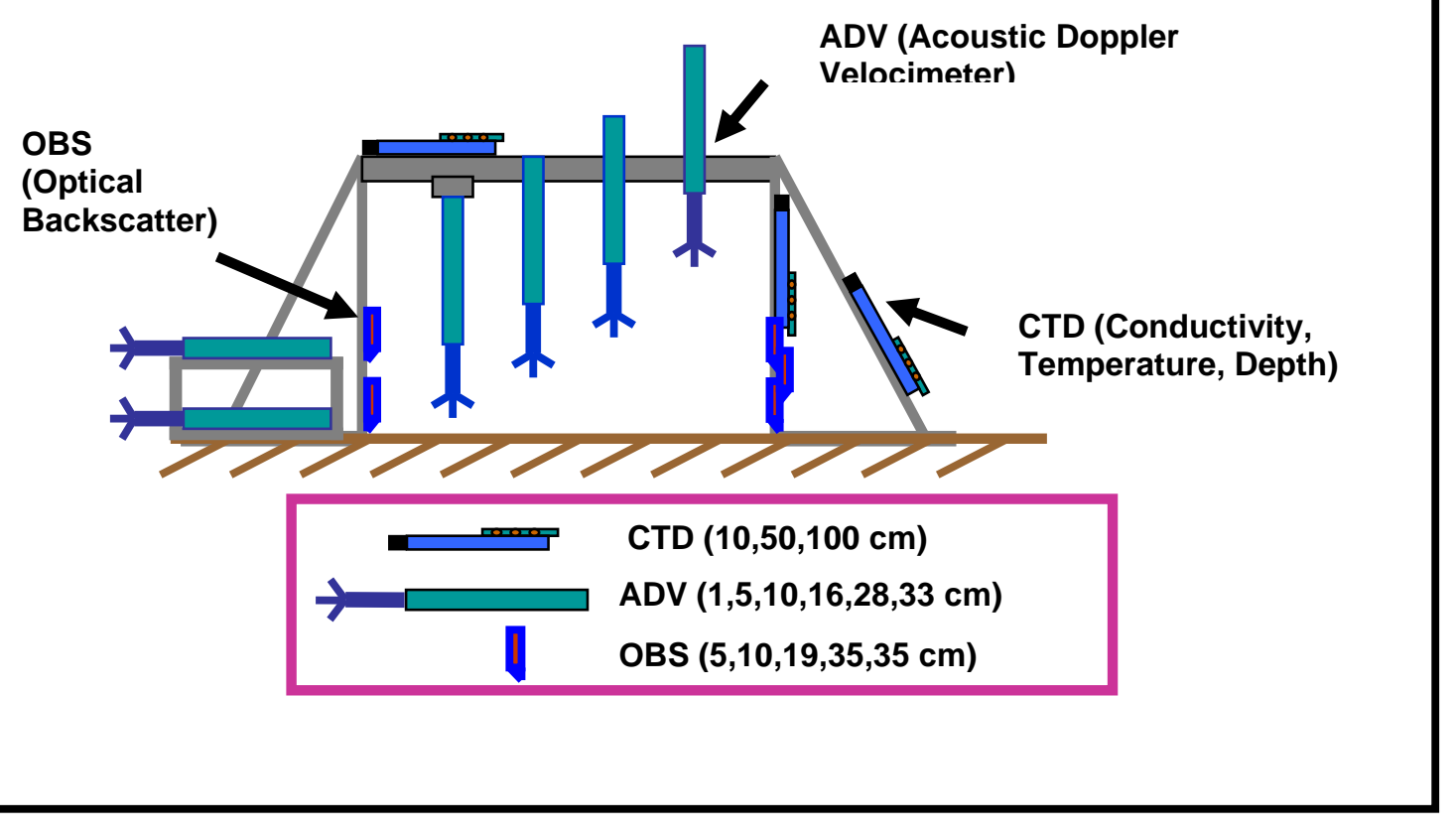

803

804

805

806

807

808

809

Figure 2: Depiction of experimental setup. Four downwards facing velocimeters were focussed $1 \mathrm{~cm}, 5 \mathrm{~cm}, 16 \mathrm{~cm}$, and $28 \mathrm{~cm}$ from the bed, while two sideways pointed velocimeters were focused at $10 \mathrm{~cm}$ and $33 \mathrm{~cm}$ off the bed. Five optical backscatter and 3 CTD instruments were placed as depicted in the figure. 

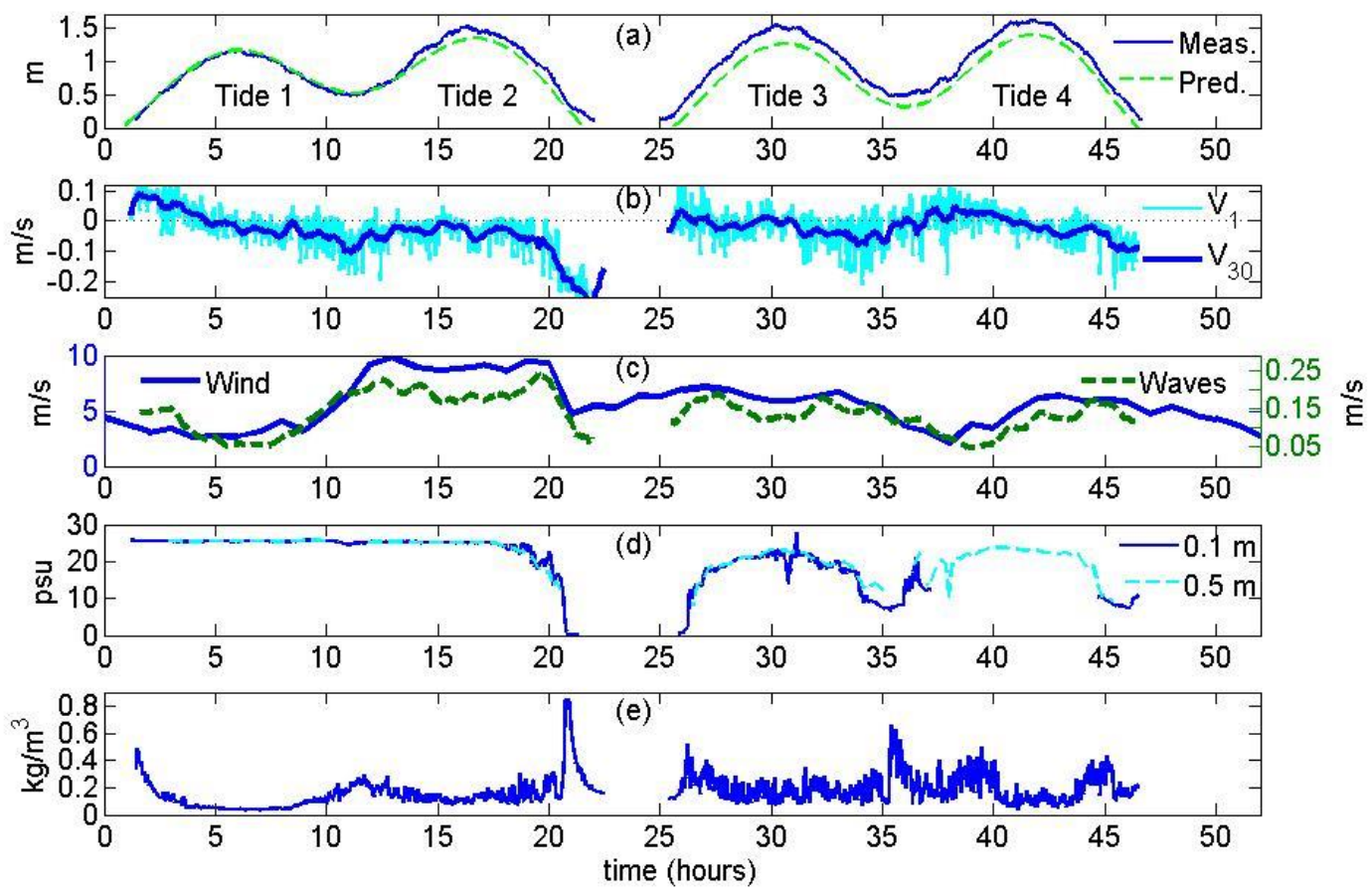

811

812 Figure 3: Plots of (a) predicted and measured tides, (b) mean velocity, (c) wind and root813 mean-square (rms) wave velocity, (d) salinity, and (e) suspended sediment concentration 814 during a meteorological event (cold front). Zero hours refers to the start of the experiment at $81516: 00$ on April $11^{\text {th }}, 2003$. In (b), both a 1 minute block average $\left(V_{l}\right)$ and a 30 minute moving 816 average $\left(V_{30}\right)$ are displayed, and zero velocity is marked with a dotted line. The rms wave 817 velocity is calculated after removing the 1 minute mean velocity over blocks of 20 minutes. 

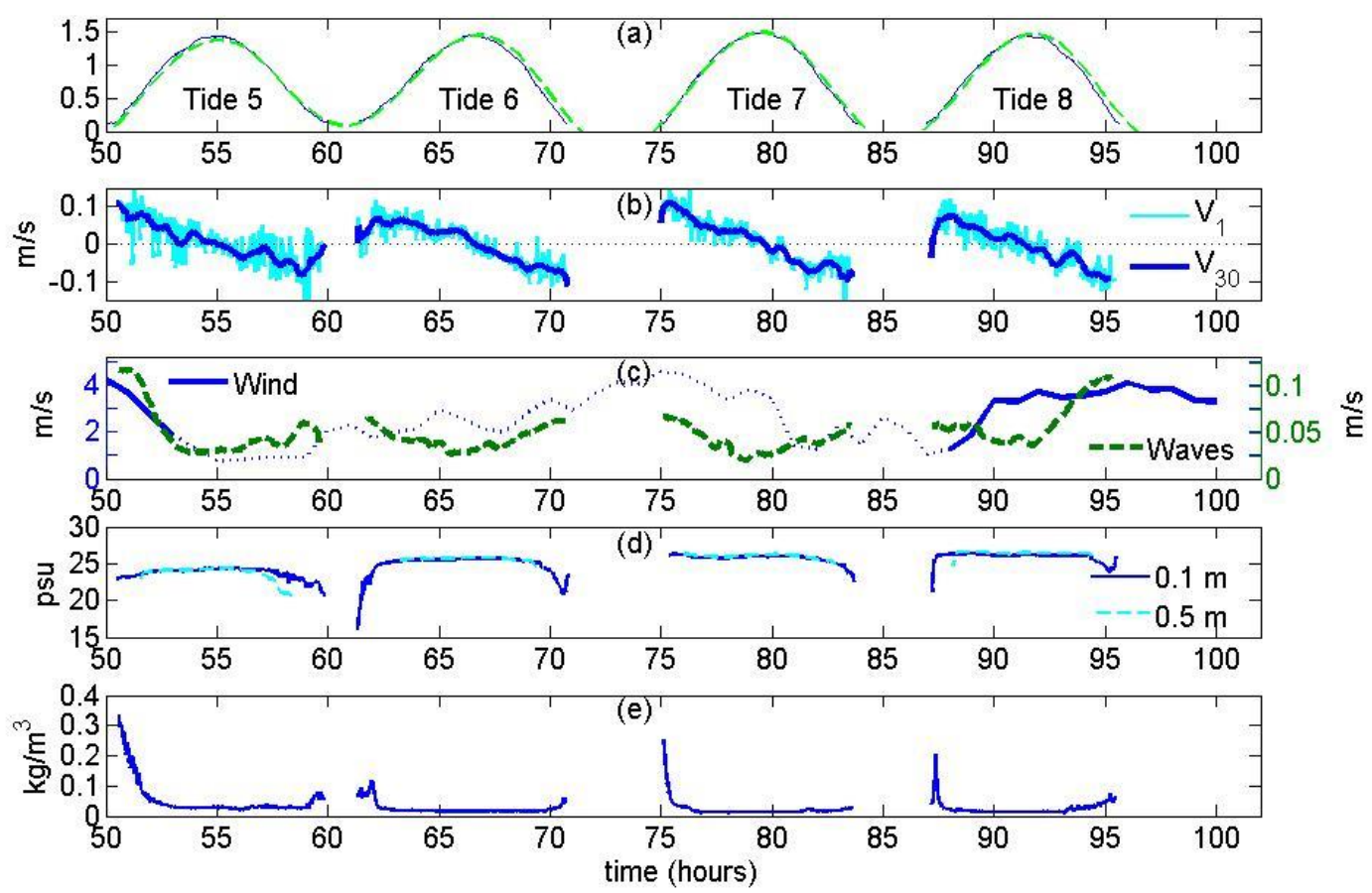

818

Figure 4: Plots of (a) predicted and measured tides, (b) mean velocity, (c) wind and rootmean-square (rms) wave velocity, (d) salinity, and (e) suspended sediment concentration after a meteorological event (tides 5-8), following the same format as Fig. 3. Offshore wind velocity blowing from North to South in (c) is depicted with a dotted line.
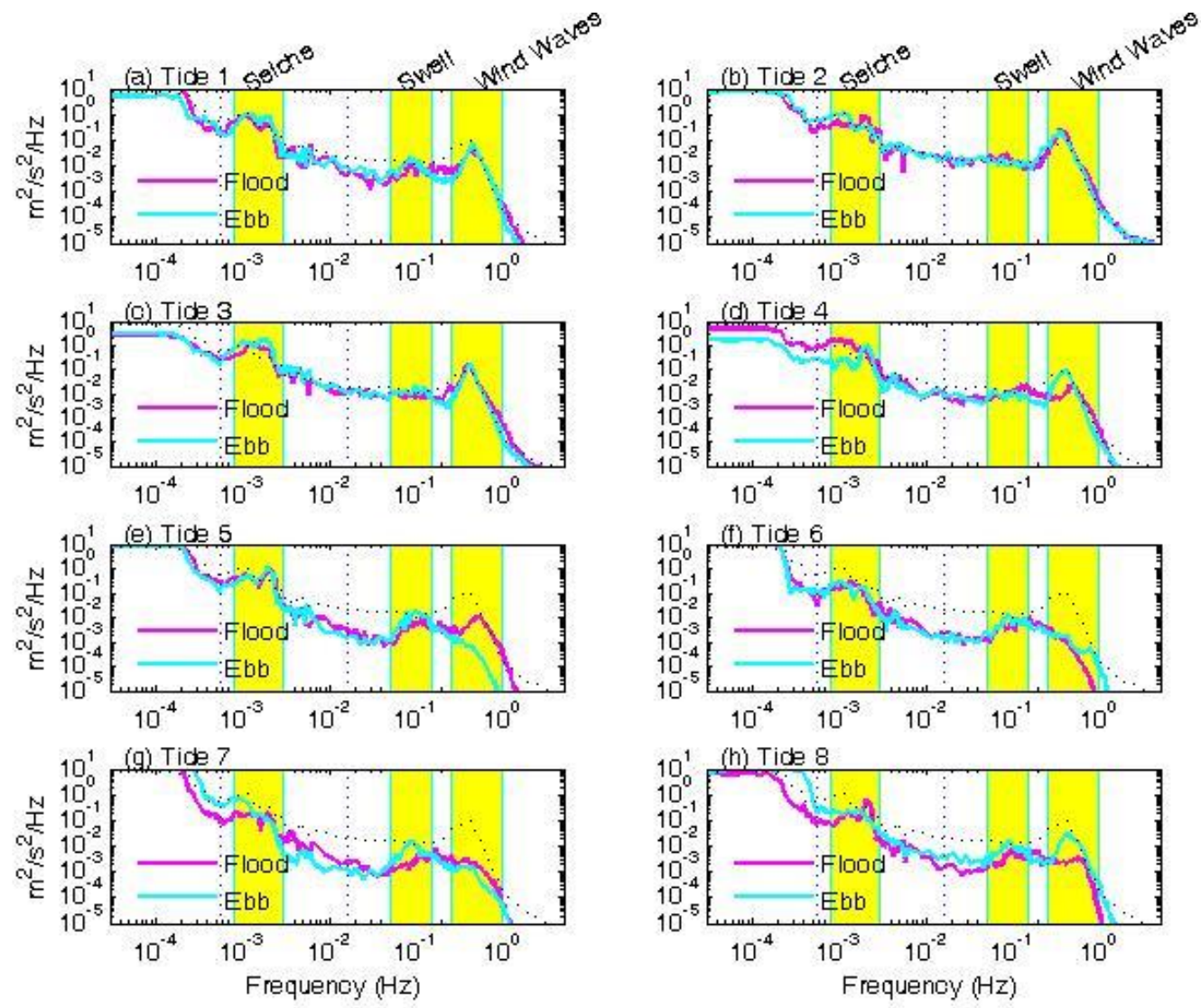

5: Comparison of the power spectrum of velocity between flood (dark shade) and ebb (light 
826 shade) over eight tidal periods. The seiche, ocean swell, and wind wave frequency bands are 827 shaded. For reference, the power spectrum during the ebb of tide 2 is presented as a dotted 828 line. The vertical dotted lines refer to frequencies of $1 / 60 \mathrm{~Hz}$ and $1 / 1800 \mathrm{~Hz}$, and depict low 829 energy band.

830 

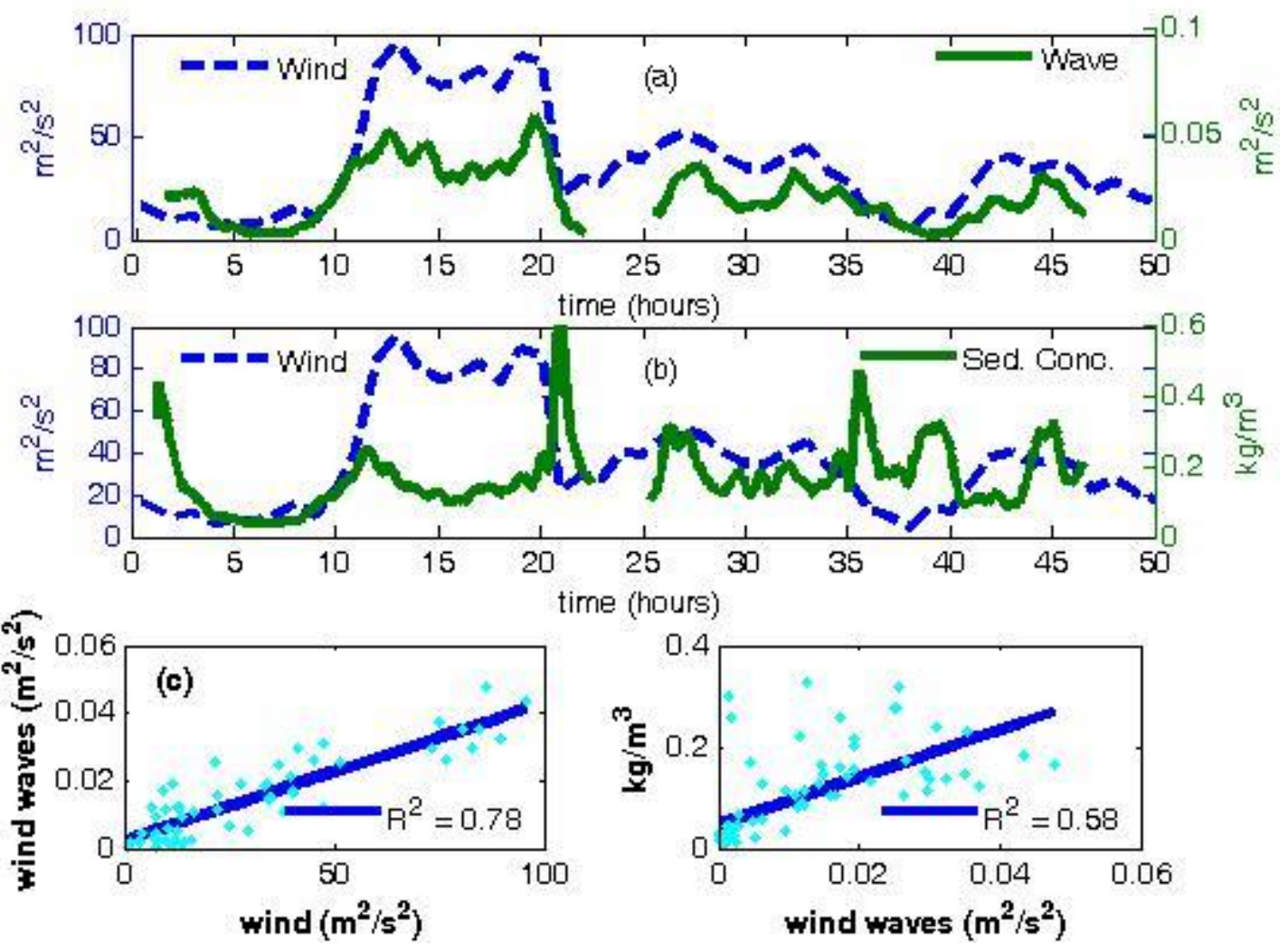

Figure 6: Evolution of wind energy (a,b), wave energy (a) and sediment concentration (b) vs. time, and scatter plots of hourly averaged wind wave energy vs. wind energy (c) and hourly averaged suspended sediment concentration vs. the hourly averaged wind wave energy (d). The sediment concentration in (b) is a 30 minute moving average. In (d), Sediment concentration measurements between hour 19-21, hour 35-41, and hour 89 are omitted because waves do not control sediment concentration values directly during this time. In addition, Wind energy between $t=55$ hours and $t=88$ hours is omitted because it is blowing towards the south (i.e., off the mudflat). Correlation of the line fit to data is given by the $\mathrm{R}^{2}$ value. 
843

844

845

846

847

848

849

850

851
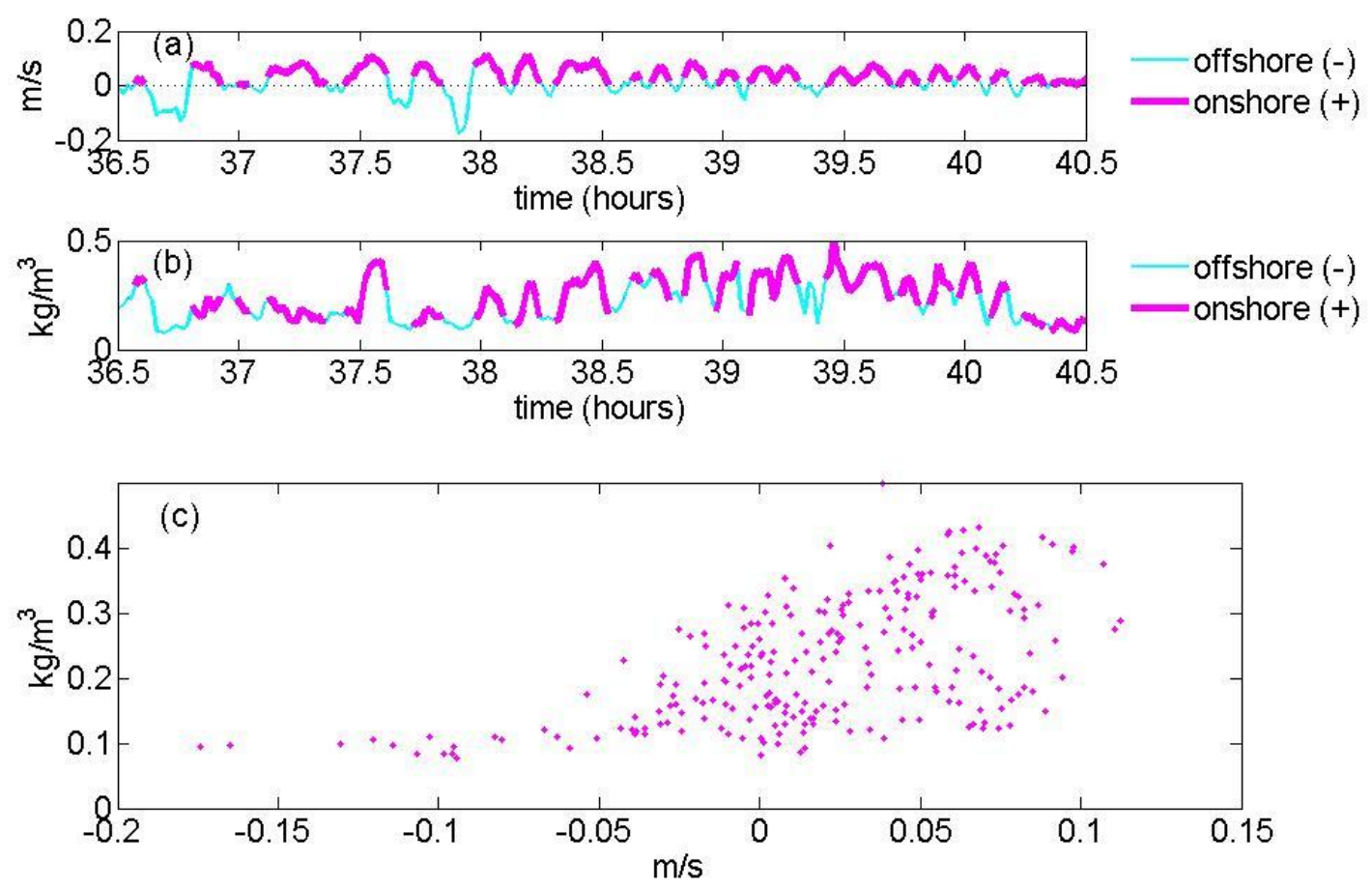

Figure 7: Plot of the (a) 1 minute mean velocity, (b) 1 minute mean SSC, and a scatter plot (c) of 1 minute mean SSC vs. 1 minute mean velocity over the time period $t=36.5$ hours to $t$ $=40.5$ hours. Periods of onshore directed velocity are shaded dark in (a) and (b).

Measurements occurred at $\mathrm{O}(0.1 \mathrm{~m})$ off the bed.
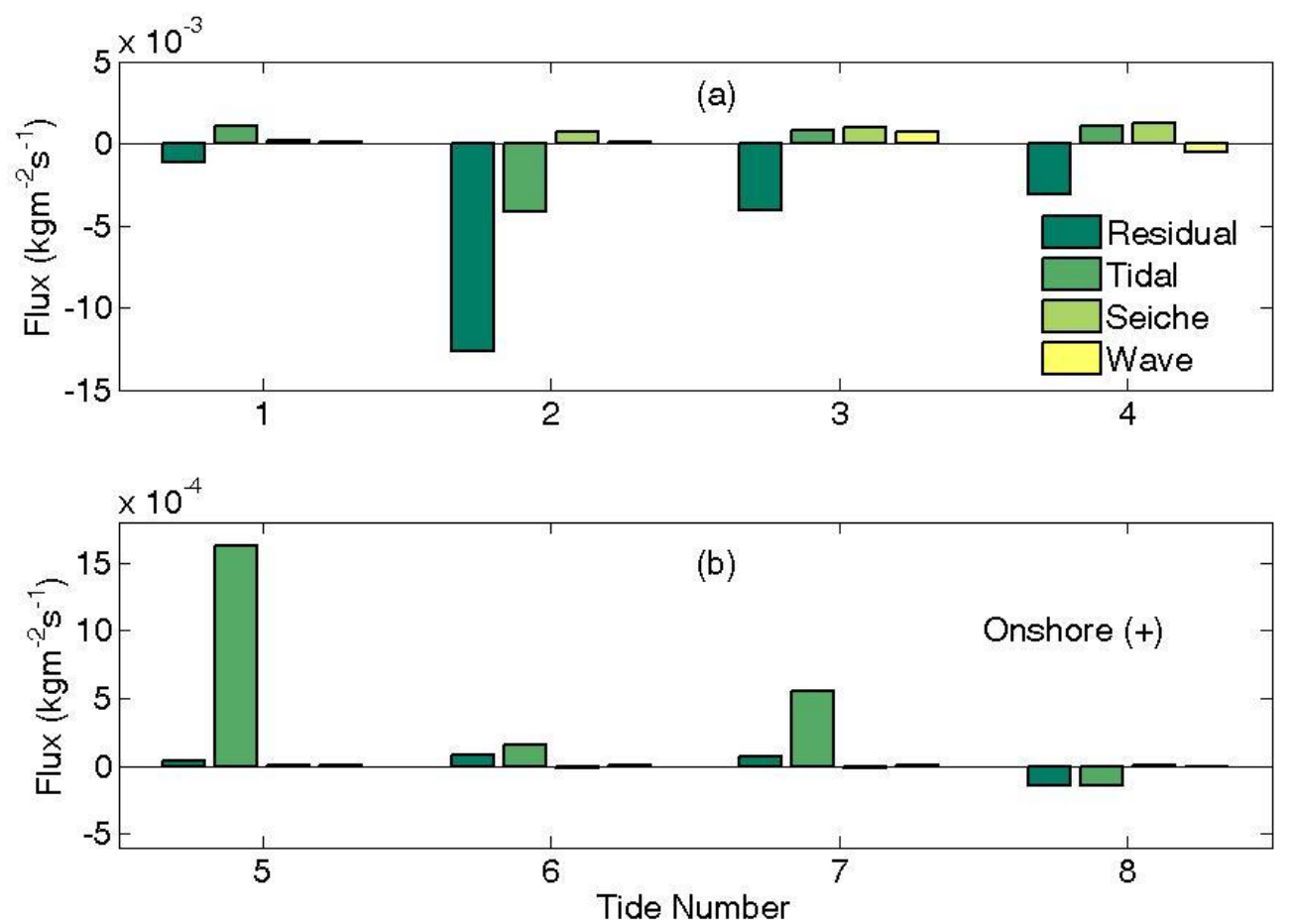
855 depicted are at the residual (tidally averaged), tidally varying, seiching, and wave frequencies.

856 The upper graph shows the tidal periods during a meteorological event characterized by

857 sustained winds of up to $9 \mathrm{~m} / \mathrm{s}$, while the lower graph denotes tidal periods during the calmer

858 period (wind speeds of $0-5 \mathrm{~m} / \mathrm{s}$ ) that follows. The onshore direction of flux is positive. 
859
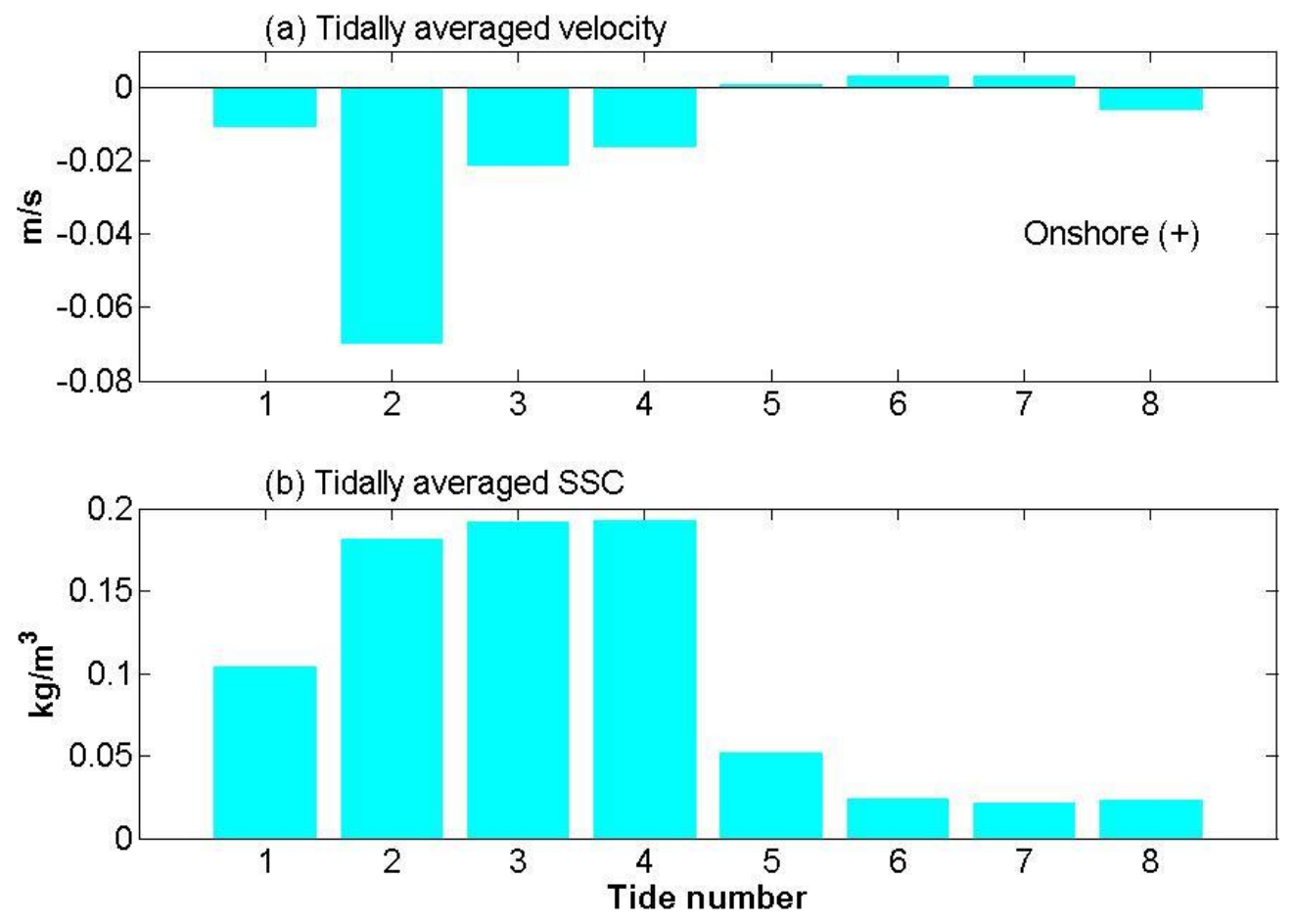

860

861 Figure 9: Residual, tidally averaged velocity (a) and suspended sediment concentration (b) 862 over the 8 tidal periods of the experiment. Tides 1-4 occur during a meteorological event 863 characterized by rainfall and sustained winds of up to $9 \mathrm{~m} / \mathrm{s}$. The remaining tides (5-8) occur 864 during a calmer, dry period with winds of $0-5 \mathrm{~m} / \mathrm{s}$. 
866

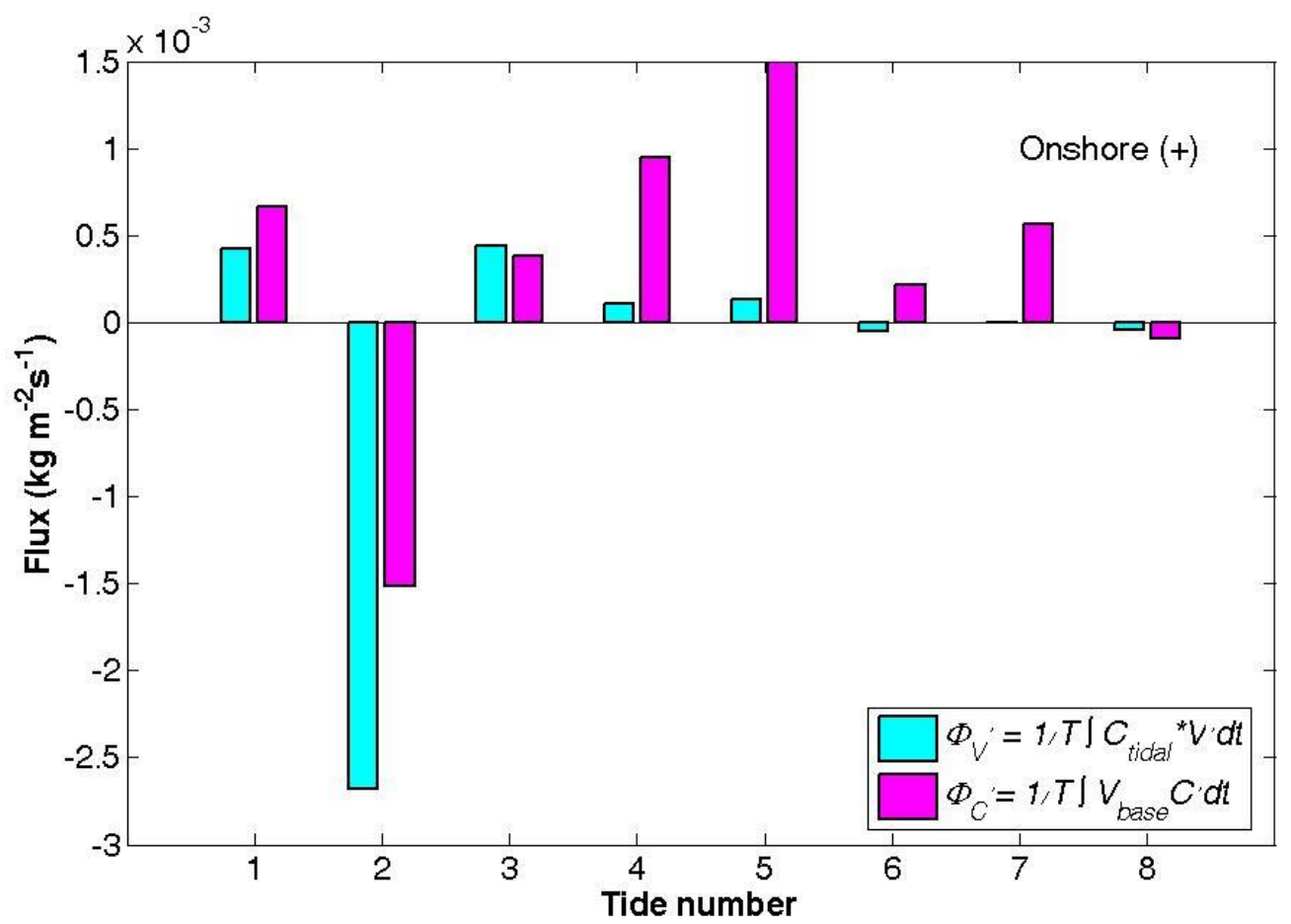

867

868

869

870

871

872

873

Figure 10: Comparison of tidally integrated sediment flux caused by asymmetries over a tidal cycle in tidally varying velocity $\left(\Phi_{V^{\prime}}\right.$ )and SSC $\Phi_{C^{\prime}}$, as defined in Eq. Tidal periods 1-4 coincided with a meteorological event with sustained wind speeds of up to $9 \mathrm{~m} / \mathrm{s}$, while tides 5-8 occurred in the calmer period that followed (winds of $0-5 \mathrm{~m} / \mathrm{s}$ ). 

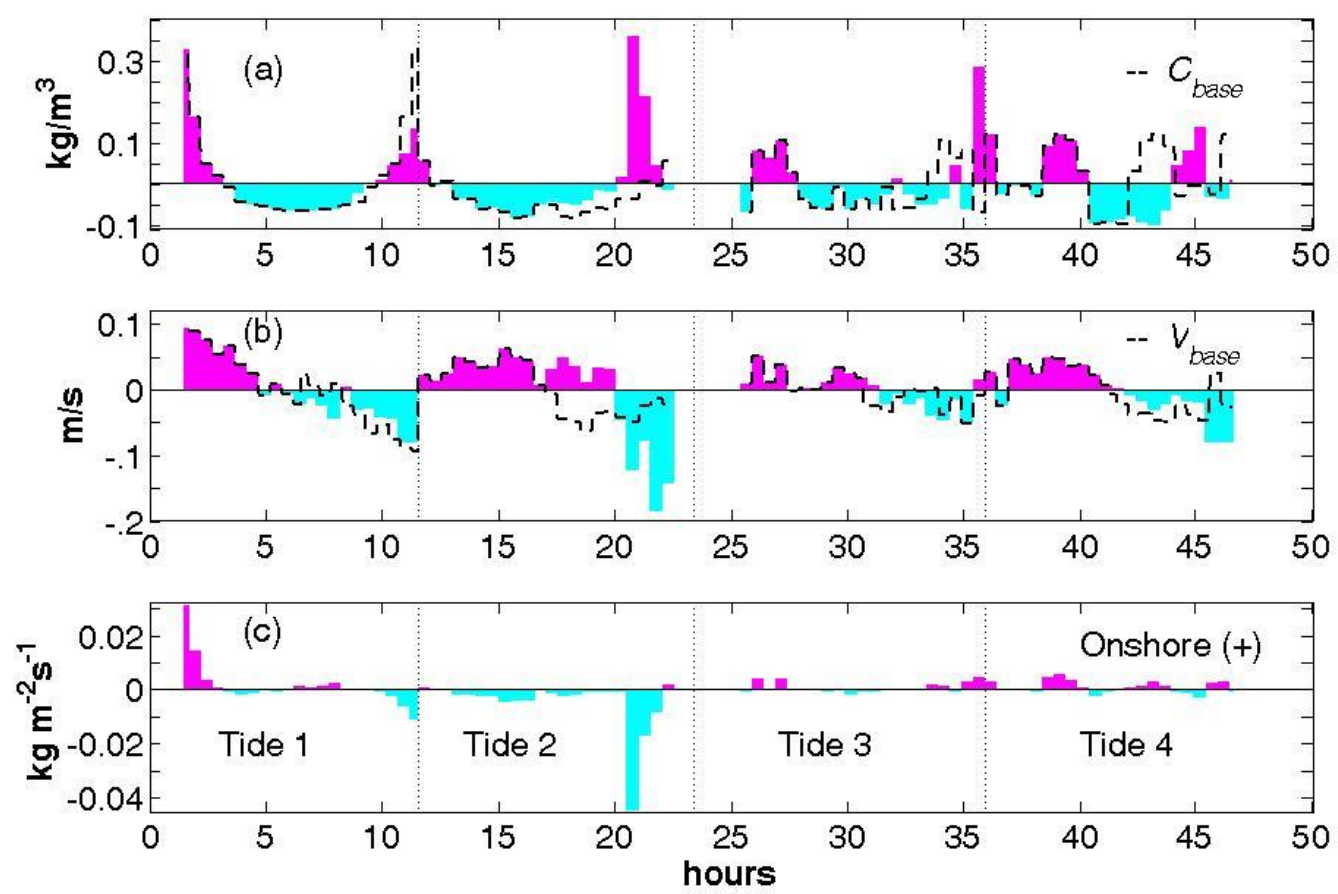

875

876

877

878

879

880

881

882

883
Figure 11: Tidal component of (a) suspended sediment concentration, (b) velocity, and (c) suspended sediment flux for tides 1-4, constructed using the 30 minute average (Eq. 5). Sediment concentrations and velocities are deviations from the tidal average. SSC and velocity components larger than the tidal mean are dark colored, while components less than the tidal mean are shaded light. Around T/2 for each tidal period, an even symmetrical function, $C_{\text {base }}$, has been constructed for SSC (dashed line in (a) and an odd function, $V_{\text {base }}$, has been constructed for velocity (dashed line in (b). The vertical dotted line delineates tidal boundaries. 

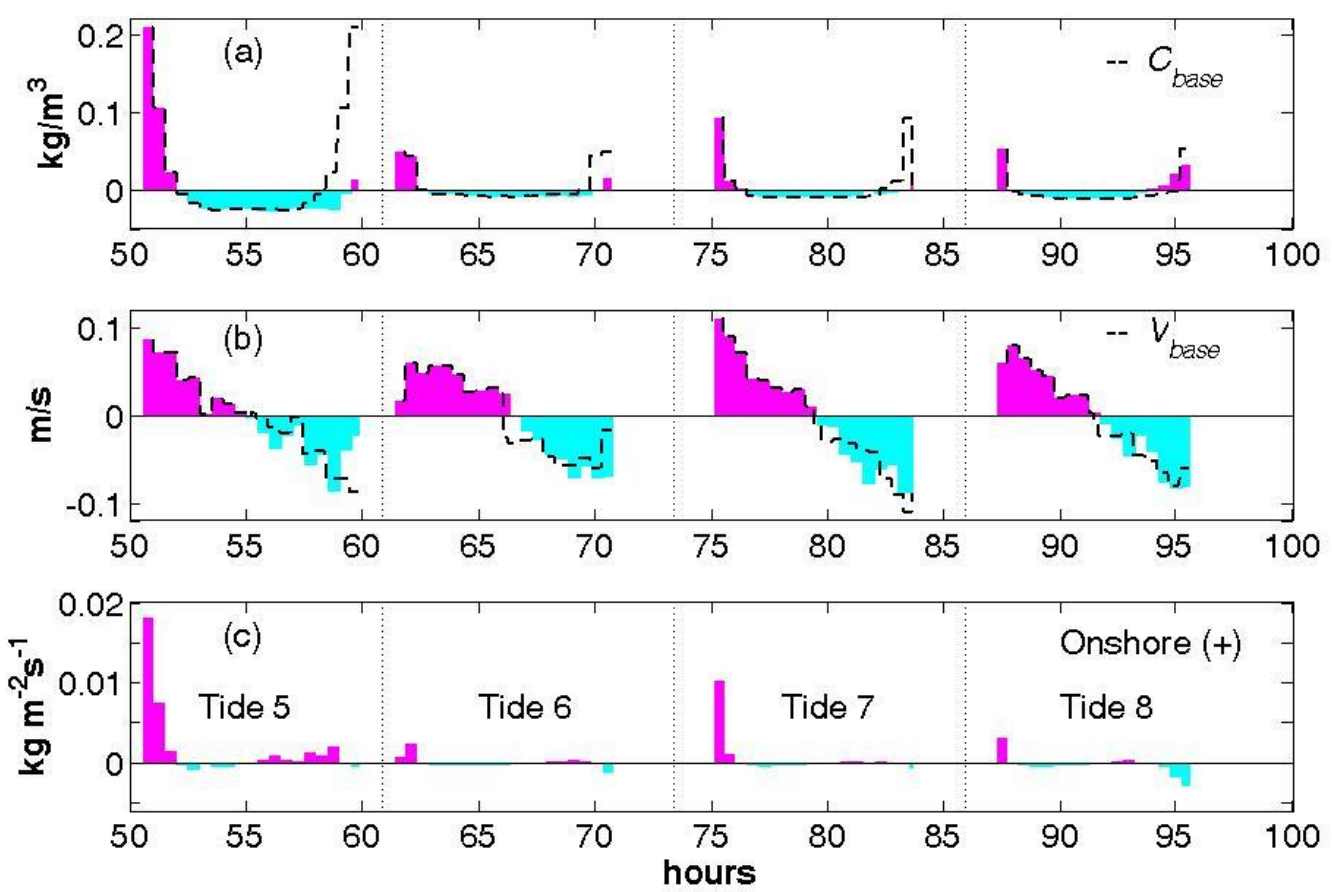

ure 12: Tidal component of (a) suspended sediment concentration, (b) velocity, and (c) suspended sediment flux for tides 5-8, following the same format as Fig. 11. 


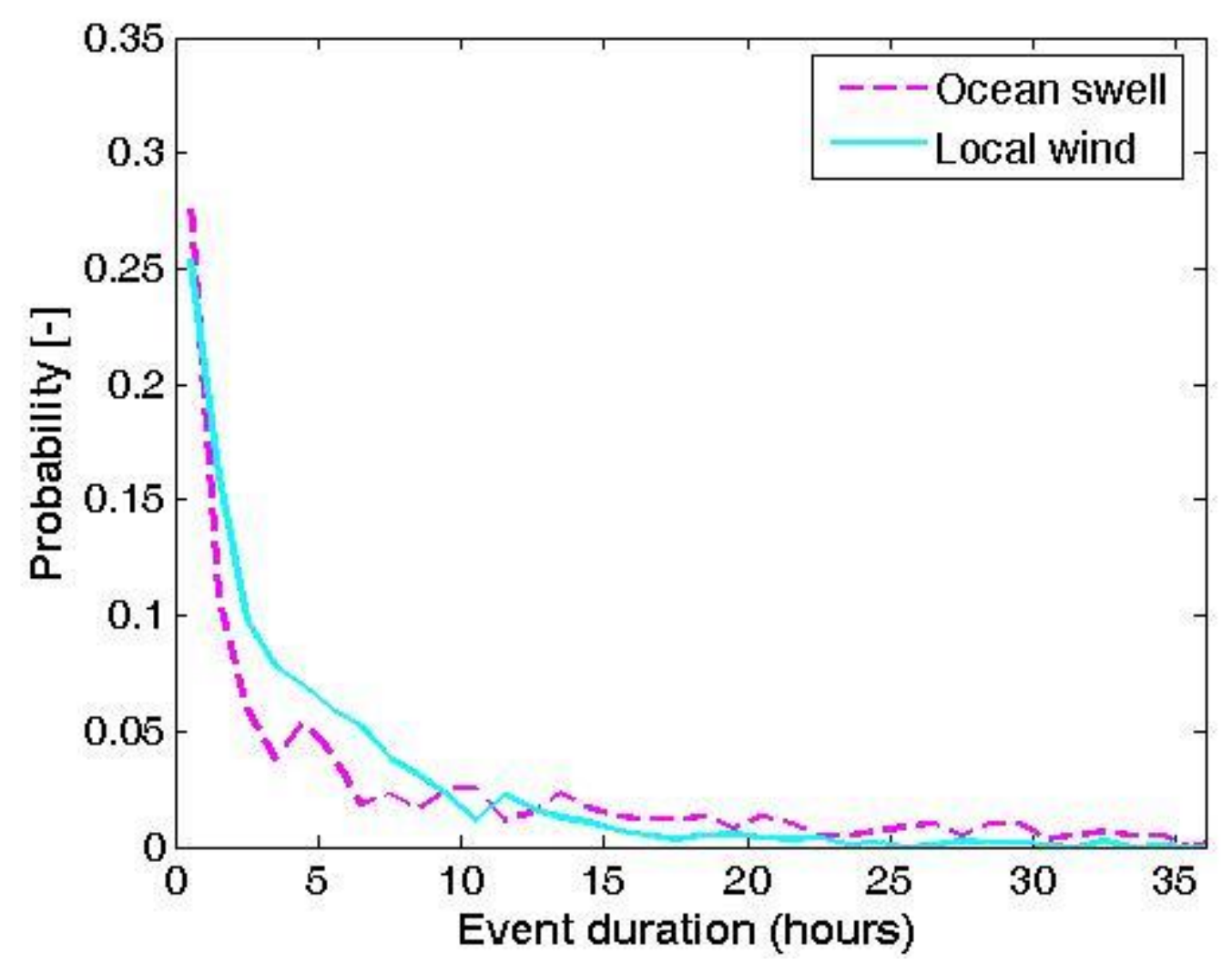

Figure 13: Probability distribution of event length for offshore waves and local wind defined from 6 years of data (1999-2005). An event is defined as an offshore wave height exceeding $2.78 \mathrm{~m}$ and a wind speed exceeding $5 \mathrm{~m} / \mathrm{s}$, which represents any measurement greater than a standard deviation from the mean. The number of consecutive measurements that exceed the event threshold determines the time scale of the event. Over half $(51 \%)$ of wind events occur over a time period of 3 hours or less, and over half $(54 \%)$ of ocean swell events occur over a time period of 5 hours or less. Only $10 \%$ of wind events, but $28 \%$ of offshore wave events, exceed 12 hours of duration. 